\title{
Structure-based docking, pharmacokinetic evaluation, and molecular dynamics-guided evaluation of traditional formulation against SARS-CoV-2 spike protein receptor bind domain and ACE2 receptor complex
}

\author{
B. Harish kumar ${ }^{1}$ - Suman Manandhar ${ }^{1} \cdot$ Chetan H. Mehta $^{2}$ - Usha Y. Nayak ${ }^{2}$ K. Sreedhara Ranganath Pai ${ }^{1}$ (i)
}

Received: 7 July 2021 / Accepted: 1 October 2021 / Published online: 18 October 2021

(C) The Author(s) 2022, corrected Publication 2022

\begin{abstract}
There is an urgent need for reliable cure and preventive measures in this hour of the outbreak of SARS-CoV-2. Siddha- and Ayurvedic-based classical formulations have antiviral properties and great potential therapeutic choice in this pandemic situation. In the current study, in silico-based analysis for the binding potential of phytoconstituents from the classical formulations suggested by the Ministry of Ayush (Kabasura Kudineer, Shwas Kuthar Rasa with Kantakari and pippali churna, Talisadi churna) to the interface domain of the SARS-CoV-2 receptor-binding domain and angiotensin-converting enzyme 2 was performed. Maestro software from Schrodinger and tools like Glide Docking, induced fit docking, MM-GBSA, molecular dynamics (MD) simulation, and thermal MM-GBSA was used to analyze the binding of protein PDB ID:6VW1 and the selected 133 ligands in comparison with drug molecules like favipiravir and ribavirin. QikProp-based ADMET evaluation of all the phytoconstituents found them nontoxic and with drug-like properties. Selection of top ten ligands was made based on docking score for further MM-GBSA analysis. After performing IFD of top five molecules iso-chlorogenic acid, taxiphyllin, vasicine, catechin and caffeic acid, MD simulation and thermal MM-GBSA were done. Iso-chlorogenic acid had formed more stable interaction with key residue among all phytoconstituents. Computational-based study has highlighted the potential of the many constituents of traditional medicine to interact with the SARS-CoV-2 RBD and ACE2, which might stop the viral entry into the cell. However, in vivo experiments and clinical trials are necessary for supporting this claim.
\end{abstract}

Keywords SARS-CoV-2 $\cdot$ Kabasura kudineer $\cdot$ Shwas kuthar rasa Talisadi churna $\cdot$ Computational docking study Molecular dynamics

\section{Introduction}

The emergence of the global pandemic caused by the novel coronavirus (COVID-19) with the epicenter in Wuhan, China, has claimed many lives and affected the world's population. Till September 26, 2021, more than 232,349,581 people have contracted corona infection, and mortality of

K. Sreedhara Ranganath Pai

ksr.pai@manipal.edu

1 Department of Pharmacology, Manipal College of Pharmaceutical Sciences, Manipal Academy of Higher Education, Manipal, Karnataka 576104, India

2 Department of Pharmaceutics, Manipal College of Pharmaceutical Sciences, Manipal Academy of Higher Education, Manipal, Karnataka 576104, India
$4,758,617$ people has been registered in the world due to SARS-CoV-2 (2021a). Coronaviruses have already been a cause for two pandemics, i.e., Middle East respiratory syndrome (MERS) and severe acute respiratory syndrome (SARS), recently in the past two decades. SARS-CoV-2 member of $\beta$-coronavirus shares $96.2 \%$ genome sequence similarity with bat coronavirus (CoV RaTG13), $79.5 \%$ with SARS-CoV, indicating that SARS-CoV-2 might have been transmitted from bats (Guo et al. 2020). Angiotensin-converting enzyme 2 (ACE 2), serving as a cell receptor for entry of SARS-CoV, was also a receptor for $\mathrm{S}$ glycoprotein present in the surface of SARS-CoV-2 (Zhou et al. 2020). CryoEM-based analysis of SARS-CoV-2 spike structure has shown the binding affinity of S-protein and ACE2 for SARS-CoV-2 is 10-20 times higher than SARS-CoV. The spike protein receptor-binding domain of SARS-CoV-2 
possesses only $40 \%$ of sequence identity with other SARSCoVs (Cascella et al. 2020). Therefore, blocking the interaction between spike protein of ACE2 receptor has been one of the major mechanisms through which enter of the virus into the cell can be prevented (Huang et al. 2020).

Social distancing, quarantine of the infected, and symptomatic treatment for the infected are currently being followed to manage the disease. No allopathic antiviral medications are available to treat this novel disease. Several attempts for vaccine development, repurposing of the known drugs have been tried out. Chloroquine (Singh and Vijayan 2020), a combination of hydroxychloroquine and azithromycin (Gautret et al. 2020), antiviral drugs like ritonavir, lopinavir have been used for treatment and found to be effective in reducing viral load and recovery. However, WHO has discontinued the trials with hydroxychloroquine and lopinavir/ritonavir on July 4, 2020, based on the observation that there was no reduction in the mortality rate of COVID-19 patients after the recommendation from the Solidarity Trial's International Steering Committee (Margaret Harris; Daniela Bagozzi 2020).

India reported its first case on January 30, 2020. There were 10.8 million cases and 154 thousand death reports till Jan 2021(2021b). Owing to the vast population and fewer doctors per 1000 people and hospital beds in India. The impact of SARS-CoV-2 on the Indian health system is enormous and challenging (Puthiyedath et al. 2020). Therefore, in this hour of need, the optimal use of traditional knowledge and AYUSH can ensure the fulfillment of scarcity in the country's health system. WHO has suggested accessing the health care system's infection prevention and control capacity, including traditional practice, healers, and pharmacy in the guidelines to support country preparedness and response (2020a). The majority of SARS-CoV-2 infected people ( $80 \%$ ) have mild symptoms (fever, fatigue, shortness of breath, loss of smell, and taste) and can be easily managed with primary medical care. Around $15 \%$ require urgent medical care with secondary health care service, and 5\% with acute respiratory distress syndrome (ARDS) require critical care in the intensive care unit (Rastogi et al. 2020).

Due to the urgent need for the treatment of the COVID, the molecules need to be selected, which can be useful and at the same time, should be safer. In this case, in silico modeling helps select the potential molecule efficiently within less time. Nowadays, all researchers use computational tools to reduce the workload and fasten the drug discovery process. Using the in silico technique, rapid analysis of a vast database using high throughput virtual screening can be done with the least time possible. In addition to this, researchers can also study the effect of the drug on the structure of the protein.

Ayurveda, Siddha, and other traditional systems, widely being practiced since ancient times, have an immense role in strengthening the human mind and body. Incorporation of allopathic medication in combination with Rasayanabased therapeutics can provide both prophylactic as well as therapeutic relief for SARS-CoV-2. The Government of India, Ministry of Ayush, has provided Guidelines for the registered practitioners from Ayurveda, Yoga, Unani, Siddha, Homeopathy, and naturopathy system to manage SARS-CoV-2 (2020b, 2020c) The Antiviral Siddha formulation, Kabasura Kudineer, has been suggested as a preventive medication for Siddha practitioners (Kiran et al. 2020). It has been described in 'Citta Vaittiyattirattu,' Siddha manuscript for treating phlegmatic fever (Aiyacuram), and Swine flu (Kaba Suram (Swine Flu), n.d.).

Similarly, Ayush guidelines for managing ARDS-like symptoms in SARS-CoV-2 condition for Ayurveda practitioners include Shwas Kuthar Rasa with Kantakari and Pippali churna, Talisadi churna. Talisadi churna, a classical formulation from Astanga Hridaya-Rajayakshma Chikitsa, is advised in acute and allergic bronchitis and exacerbated asthma attacks (Patra et al. 2011). Shwas kuthar rasa, a formulation based on Rasa aushadhis, has been prescribed for moderate to severe symptoms of SARS-CoV-2. In this current study, we have chosen the classical formulations from the guidelines provided by Ayush and evaluated the potential of the active constituents for the inhibition of the ACE2 receptor so that the entry of the SARS-CoV-2 virus can be prevented.

\section{Materials and methods}

All the computational calculations were performed using Schrodinger Maestro Suit using different modules such as LigPrep, SiteMap, Protein Preparation Wizard, Grid Generation, Glide Docking, MM-GBSA, induced fit docking, and Desmond molecular dynamic simulation.

\section{Ligand preparation}

The structure of chief constituents of the plants used in the classical formulations, namely Kabasura Kudineer (Kiran et al. 2020), Shwas Kuthar Rasa with Kantakari (Janadri et al. 2015) and Pippali churna, Talisadi churna (Tekuri et al. 2019), was downloaded from PubChem. These formulations were mentioned in the guidelines provided by Ayush for Ayurvedic and Siddha practitioners. A total of 133 selected ligands were prepared using the LigPrep tool to get the geometry optimized structures at $\mathrm{pH} 7.0 \pm 2.0$ with the chirality of the ligand determined by its 3D structure (Schrödinger 2018-3, LLC, New York). 


\section{Protein preparation, sitemap, and grid generation}

The protein crystal structure of the SARS-CoV-2 Chimeric Receptor-binding domain and Angiotensin-converting enzyme 2 (PDB ID: 6VW1) (Shang et al. 2020) required for performing the computational study was collected from the Protein Data Bank). The Schrodinger module, namely Protein Preparation Wizard, was used for processing the protein structure where it performed in three steps, such as import and process, review, and modify, followed by refinement. In the first step, the protein structure was processed by adding the hydrogen and missing side chains and assigning the bond orders. In the second step, the protein was reviewed for the presence of required side chains, only side chains A and E were selected, and the protein was modified by deleting other side chains. In the last step or third step, H-bonds were assigned and optimized, followed by the removal of water molecules which beyond 3.0 A. Finally, the restrained minimization was performed for the modified protein by using the OPLS3e force field. As the PDB structure contained many chains, only Chain E, which is SARS-CoV-2 chimeric RBD and Chain A ACE2 receptor, was retained as shown in Fig. 1, and other chains were deleted. The selected protein was without the bound ligand structure; hence SiteMap was performed, which helps identify the probable binding site for the ligand (Halgren 2009). The binding site, which showed the highest site score and was present in the interphase of Chain A and E, was selected for further grid generation using the Glide-Receptor Grid Generation module. The remaining parameters were used by default (Halgren 2007; Madhavi Sastry et al. 2013).

\section{Molecular docking and binding free energy calculation}

The molecular docking was performed by docking the prepared ligands on the selected site of the protein using the Glide module. The receptor grid file and the ligands to be docked from the workspace were selected, and the calculation was performed using extra precision docking. The results were analyzed based on the docking score and molecular interaction formed between the ligand and the protein molecule. The best ligands molecules were selected and subjected to the MM-GBSA and induced fit docking (Halgren et al. 2004; Friesner et al. 2006). Selected ligand and protein structures were considered for performing the MM-GBSA calculations. All the calculations were performed by using VSGB (variable surface generalized born) as the solvent model and OPLS3e as the force field. This
Fig. 1 Structure of protein complex (PDB ID 6VW1) containing SARs-Cov-2 chimeric receptor-binding domain (chain E) and angiotensin-converting enzyme 2 (Chain A)

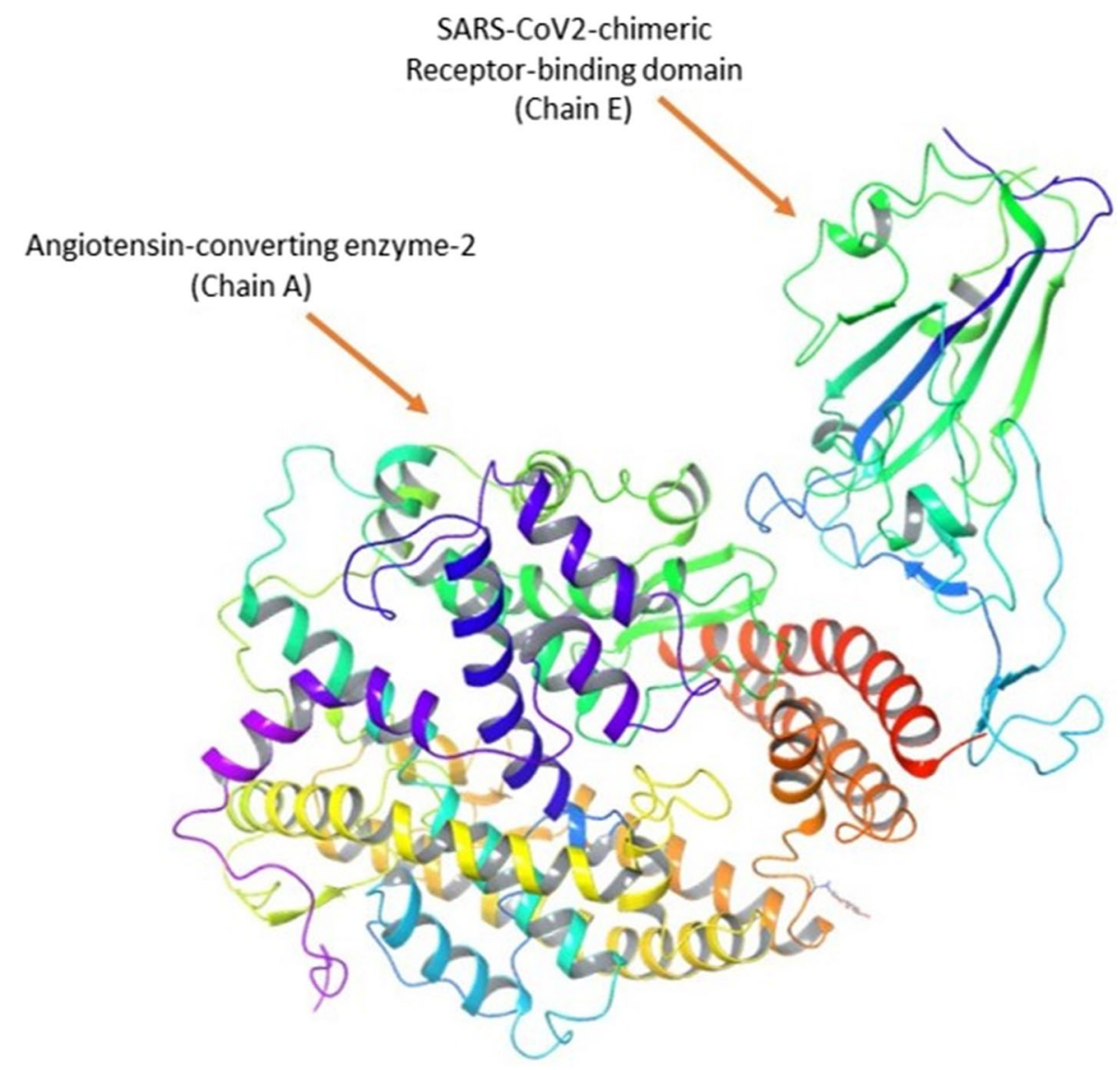




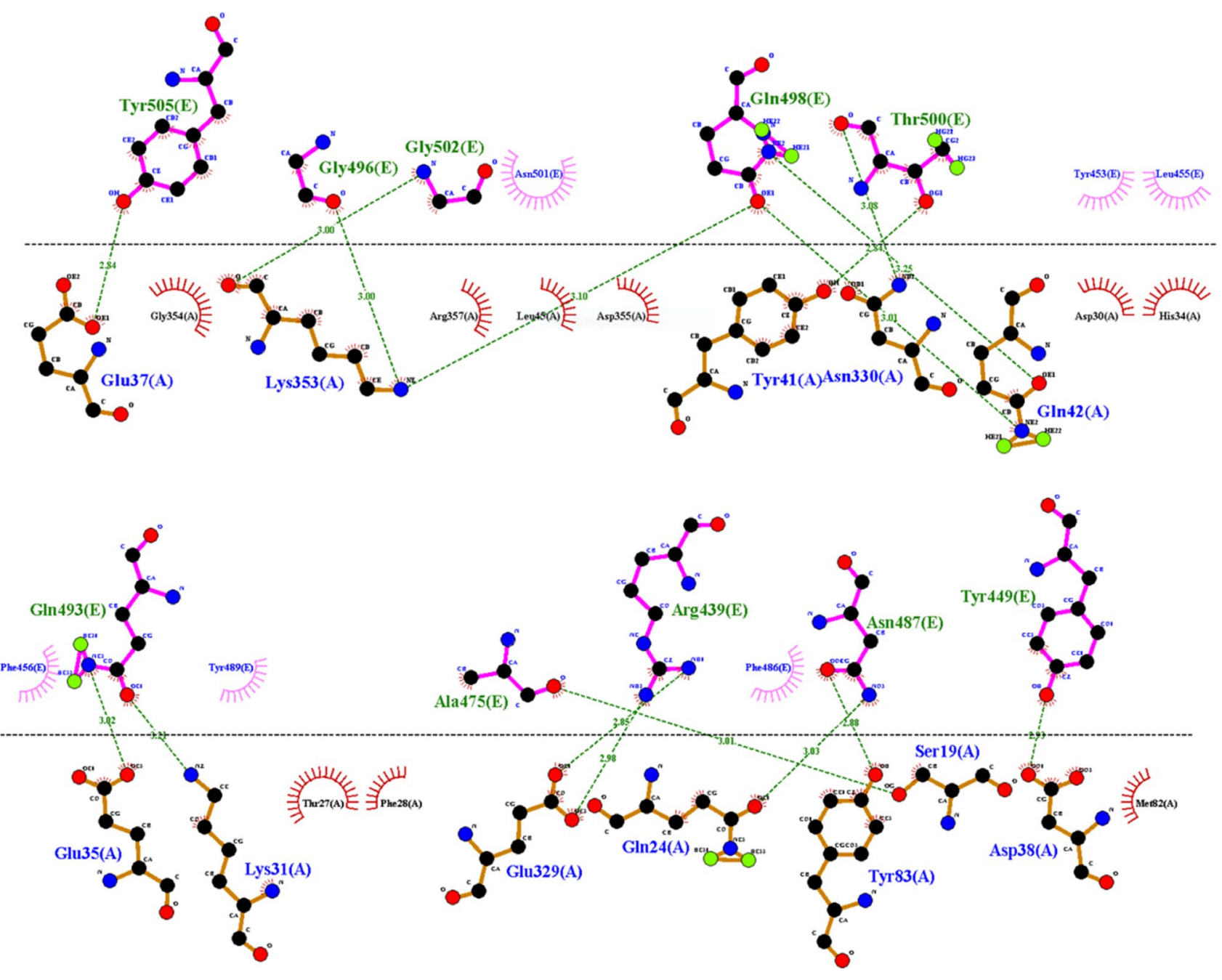

Fig. 2 Dimplot of protein complex of SARs-Cov-2 chimeric receptor-binding domain and angiotensin-converting enzyme 2

Table 1 Sitemap analyses for protein complex containing SARS-CoV-2 chimeric receptor-binding domain and angiotensin-converting enzyme 2

\begin{tabular}{|c|c|c|c|c|}
\hline Title & Site score & Dscore & Volume & Residues \\
\hline Chain A \& E site 3 & 1.047 & 1.069 & 470.93 & $\begin{array}{l}\text { Chain A: } 276,279,288,289,290,291,292,294,346,365,366,367,370,371,374,375,406,409,410 \text {, } \\
\quad 413,428,434,437,438,441,442,445,446,449,515,518,519,522\end{array}$ \\
\hline Chain A \& E site 2 & 1.027 & 1.048 & 636.26 & $\begin{array}{l}\text { Chain A: } 85,90,91,92,94,95,98,99,101,102,103,104,107,193,194,195,196,202,205,206,208,2 \\
09,210,211,212,219,391,392,396,397,560,561,562,563,564,565,566,569,714\end{array}$ \\
\hline Chain A \& E site 1 & 1.018 & 1.051 & 968.63 & $\begin{array}{l}\text { Chain A: } 26,29,30,32,33,34,35,37,38,40,70,73,74,77,92,93,95,96,99,100,102,103,104,105,10 \\
6,324,346,347,349,350,352,353,354,355,356,375,378,382,385,386,387,389,390,391,392,3 \\
\text { 93,394,398,401,402,505,510,514,515 } \\
\text { Chain E: } 403,405,406,408,409,416,417,453,493,494,495,496,497,501,502,503,504,505\end{array}$ \\
\hline Chain A \& E site 5 & 0.781 & 0.804 & 137.88 & $\begin{array}{l}\text { Chain E: } 335,336,337,338,339,340,342,343,344,347,364,365,367,368,371,373,374,436,437 \text {, } \\
\quad 438,440,441,509\end{array}$ \\
\hline Chain A \& E site 4 & 0.744 & 0.626 & 102.21 & Chain E: $454,456,457,458,459,467,469,471,472,473,474,480,482,491$ \\
\hline
\end{tabular}

calculation helps in calculating the relative binding affinity of the ligands toward the selected protein.

\section{Induced fit docking (IFD)_extra precision}

The extra precision induced fit docking was performed by docking the selected ligands on the rigid protein using the 


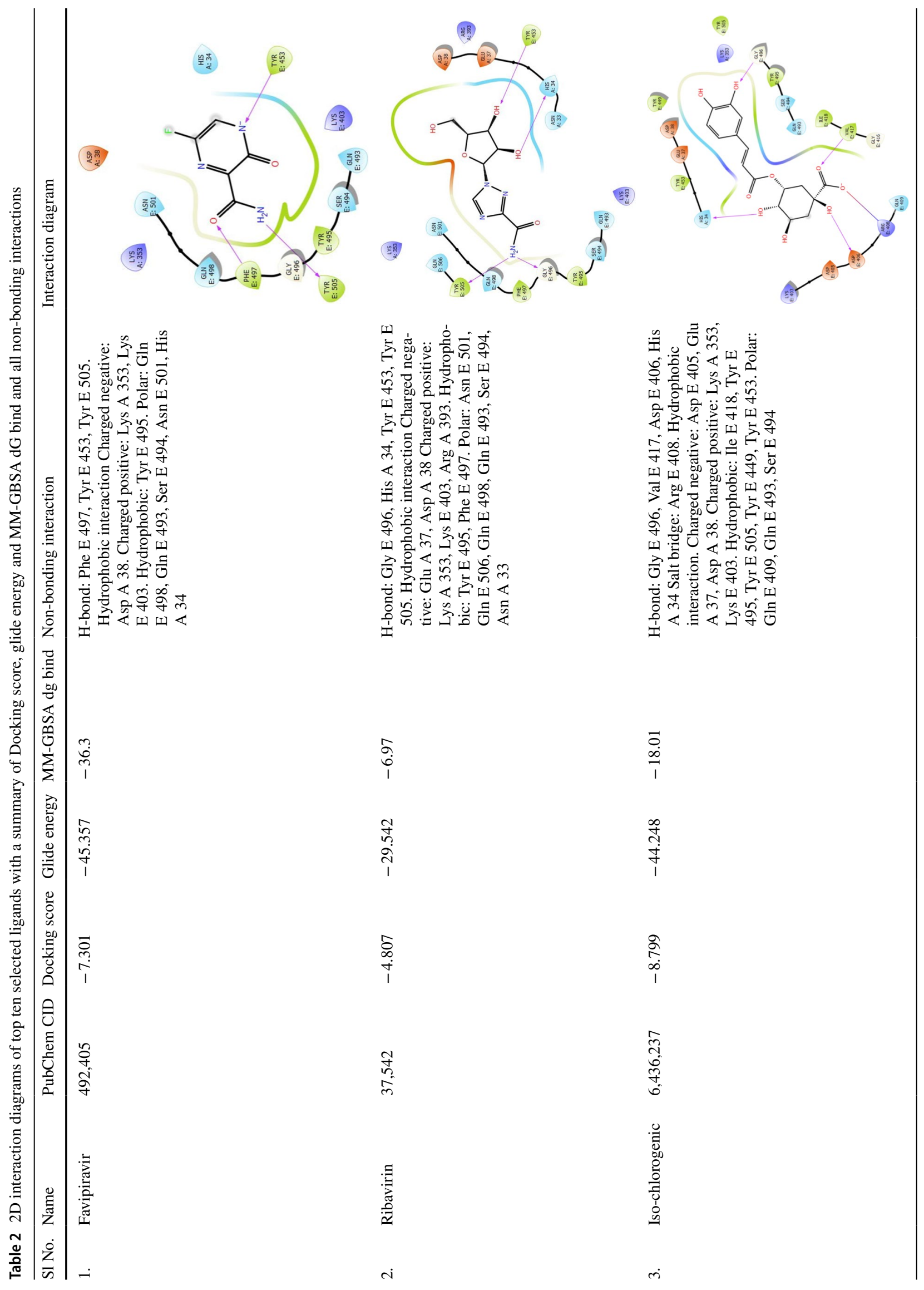




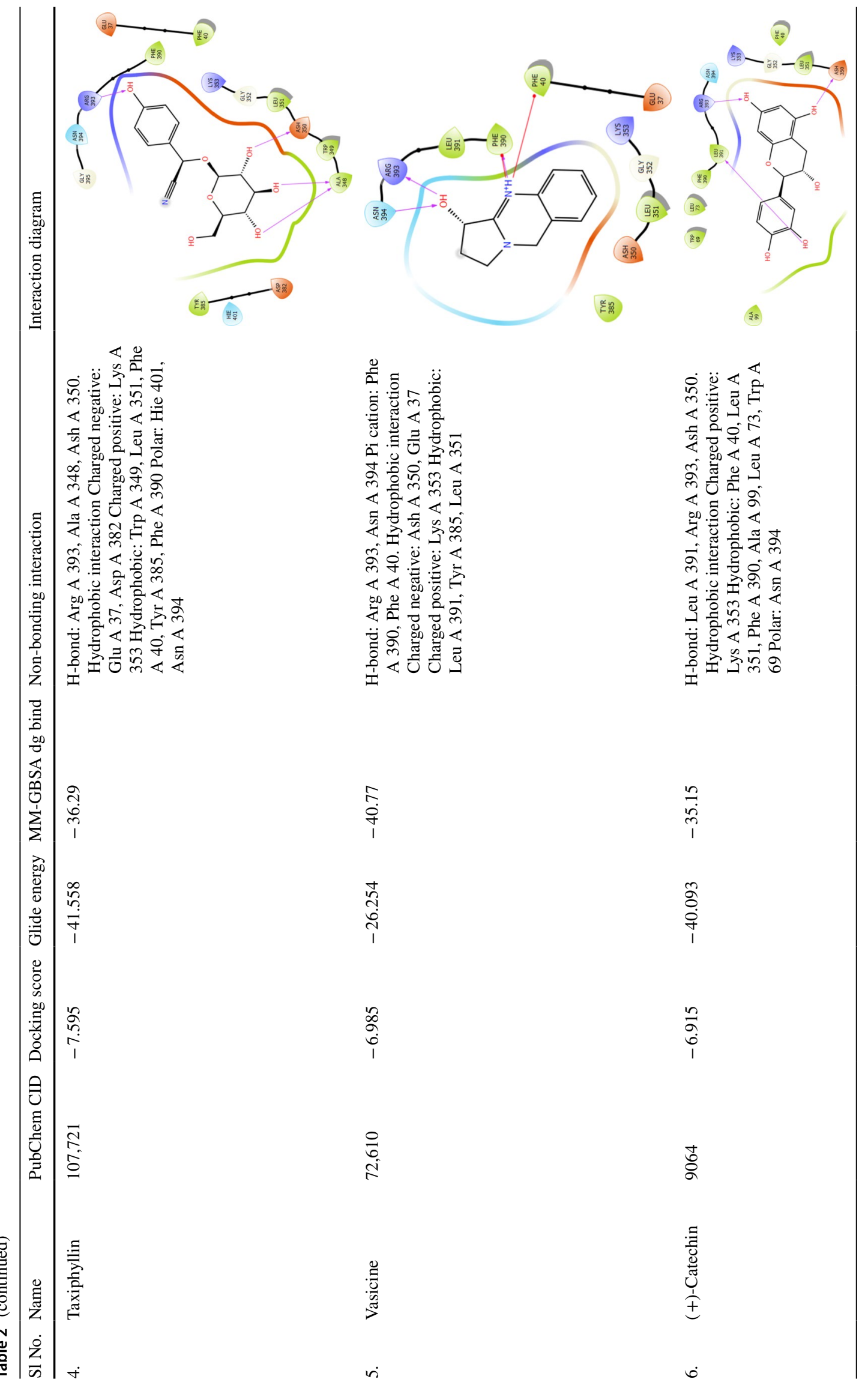




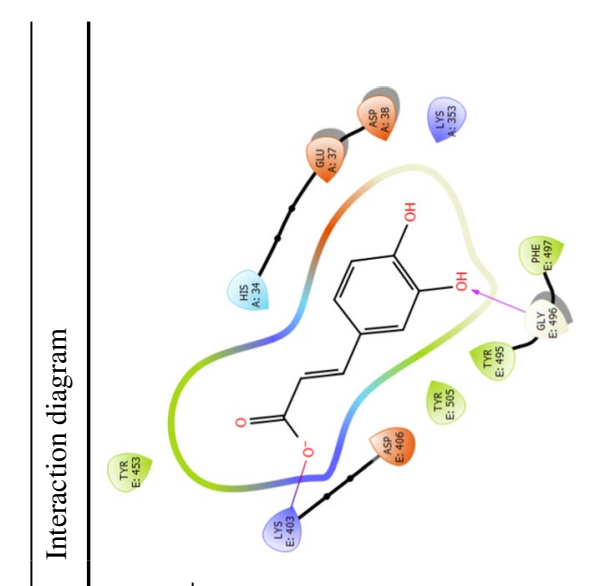

E

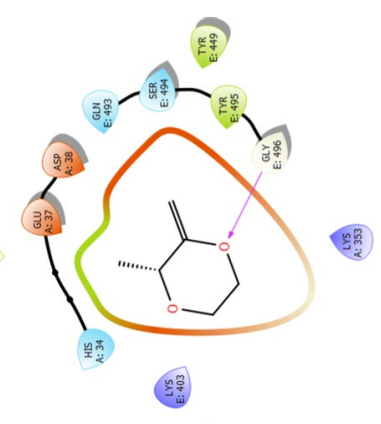

\&:

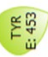
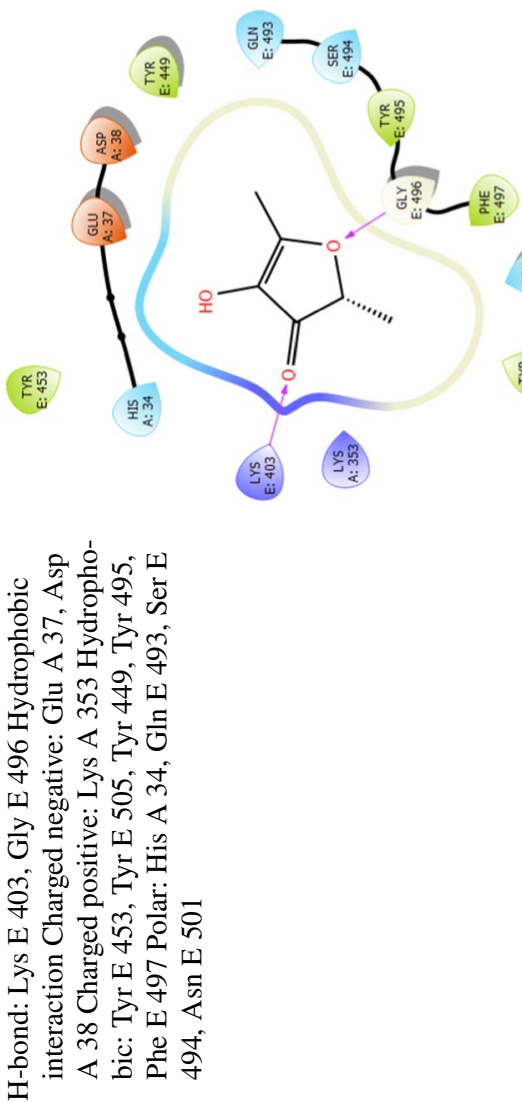

ن

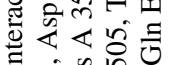

an

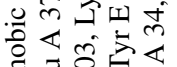

产寻京舟

원된

곡데

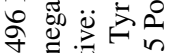

되

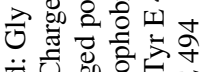

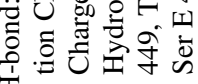

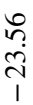

0
0
$\substack{0 \\ 1}$
1

$\stackrel{n}{n} \underset{n}{n}$

$\hat{s}$
$\dot{+}$
1

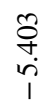

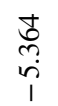

8
के
ते

के

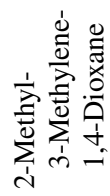

$\infty$
ڤे

宊

$a$ 


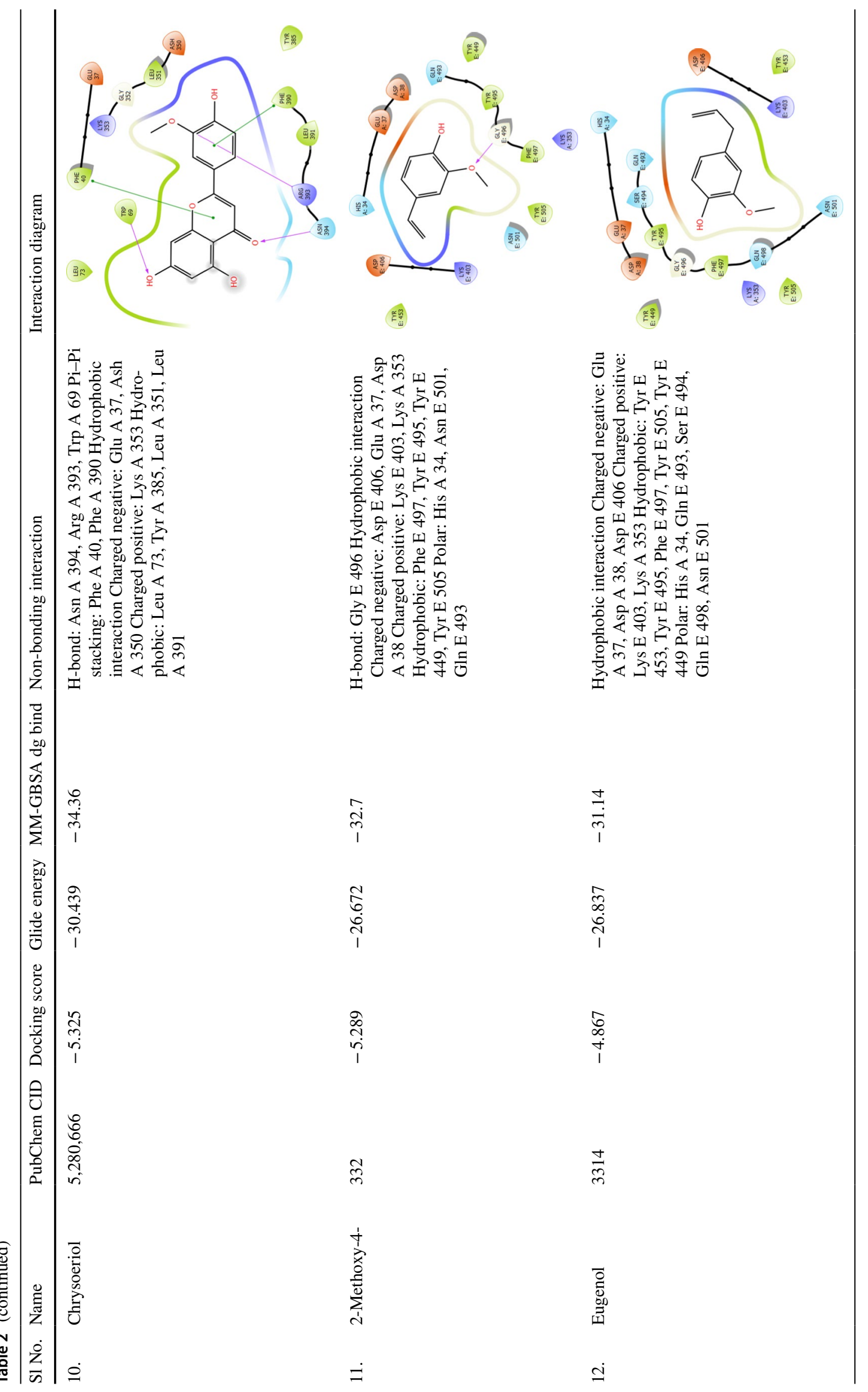


Table 3 ADME prediction of the top ten selected ligands by using various parameters like solubility, partition, toxicity, absorption and draggability

\begin{tabular}{|c|c|c|c|c|c|c|c|c|}
\hline S1 No. & Name & $\mathrm{QP} \log \mathrm{Po} / \mathrm{w}$ & QPlogS & QPlogHERG & QPPCaco & $\begin{array}{l}\% \text { Human Oral } \\
\text { Absorption }\end{array}$ & PSA & Rule of Five \\
\hline 1. & Iso-chlorogenic acid & -0.301 & -2.218 & -2.914 & 1.979 & 17.531 & 184.001 & 1 \\
\hline 2. & Taxiphyllin & -1.499 & -0.539 & -4.75 & 30.763 & 44.801 & 150.57 & 0 \\
\hline 3. & Vasicine & 1.892 & -2.465 & -4.083 & 2398.587 & 100 & 37.543 & 0 \\
\hline 4. & $(+)$-Catechin & 0.448 & -2.662 & -4.847 & 49.179 & 59.848 & 117.119 & 0 \\
\hline 5. & Caffeic Acid & 0.545 & -1.293 & -2.169 & 22.354 & 54.287 & 95.571 & 0 \\
\hline 6. & 2-Methyl-3-Methylene-1,4-Dioxane & 0.767 & -0.233 & -2.386 & 9906.038 & 100 & 16.996 & 0 \\
\hline 7. & Furaneol & 0.225 & -0.825 & -2.715 & 1104.367 & 82.727 & 60.06 & 0 \\
\hline 8. & Chrysoeriol & 1.761 & -3.633 & -5.058 & 115.81 & 74.193 & 107.153 & 0 \\
\hline 9. & 2-Methoxy-4-Vinylphenol & 1.908 & -1.623 & -3.749 & 3043.607 & 100 & 29.937 & 0 \\
\hline 10. & Eugenol & 2.661 & -2.387 & -3.954 & 3043.414 & 100 & 29.952 & 0 \\
\hline
\end{tabular}

induced fit docking module. While performing the IFD, the receptor and ligand van der Waals scaling was maintained to 0.50 and generated the maximum of 20 poses of the protein with ligands. The calculations were performed by considering the standard precision protocol. The best pose of the ligand-protein complex was selected for performing the MD simulation (Sherman et al. 2006b, 2006a).

\section{Molecular dynamic simulation (MD)}

The ligand-protein complex was selected, and the system was built by using a system builder module of orthorhombic box shape with the size of $10 * 10 * 10 \AA$ and then predefined SPC (simple point charge) solvent model, OPLS3 as a force field was selected, For all system required number of sodium/chloride ions were added to neutralize by maintaining the salt concentration of $0.15 \mathrm{M}(\mathrm{Na}+$ and $\mathrm{Cl}-)$. The built system was minimized to relax a model system into a local energy minimum for 100 ps simulation time. The minimized system was used for performing the MD simulation for $100 \mathrm{~ns}$ using NPT (constant temperature and constant pressure ensemble) ensemble class at $300 \mathrm{~K}$ temperature and 1.01325 bar pressure. After performing MD simulation, thermal MM-GBSA was performed using trajectory generated from MD simulation for the protein-ligand complex. The MD simulation results were analyzed by generating the simulation interaction diagram (Bowers et al. 2006).

\section{Result}

\section{Analyses of SARS-CoV-2 and ACE2 receptor-interacting residues}

To enter SARS-CoV-2 into the cell, the receptor-binding domain of SARS-CoV-2 should interact with the ACE2 receptor. The interaction between the ACE2 receptor and SARS-CoV-2 RBD was analyzed by dimplot using LigPlot software (Laskowski and Swindells 2011). From the plot, all amino acid pairs which form a hydrogen bond (H-bond) between chain A and $\mathrm{E}$ are represented in Fig. 2. In his study, these interacting residues were targeted to inhibit the entry of the SARS-CoV-2 using the database created from selected Ayurvedic and Siddha formulations.

\section{Docking site identification using the sitemap}

To determine the best site for the docking of the ligands, a sitemap analysis of the protein complex was done. The five best-docking sites were determined, the Dscore and site score are shown in Table 1. Among these sites, the one with a Dscore (1.051) and site score more than 1 (site 1-1.018) covering the amino acids involved in hydrogen bond formation between the protein complex as analyzed by dimplot was selected for grid generation and docking of the selected molecules. 

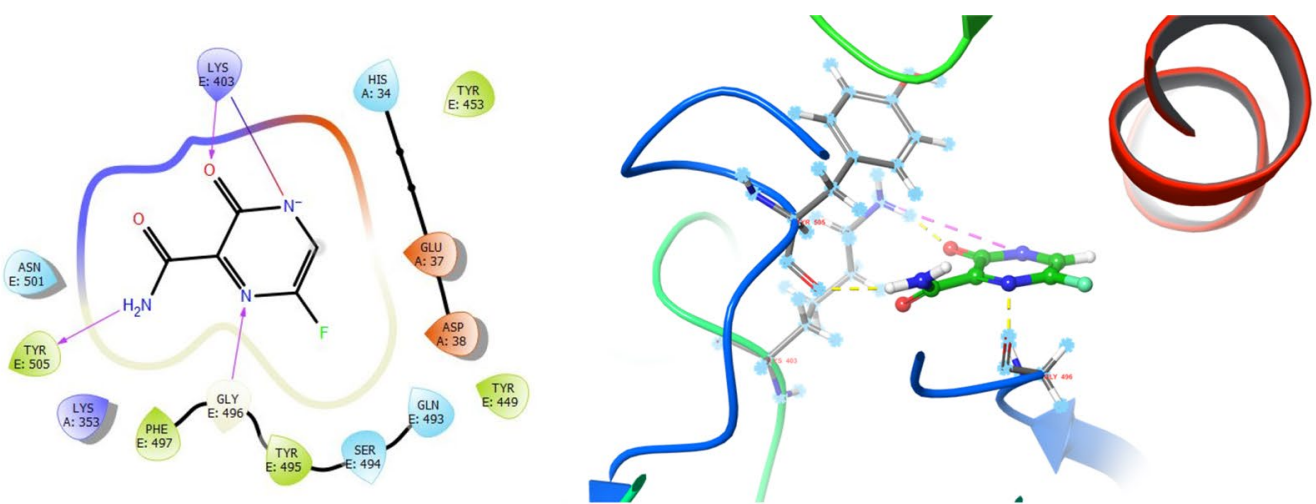

\section{Favipiravir}

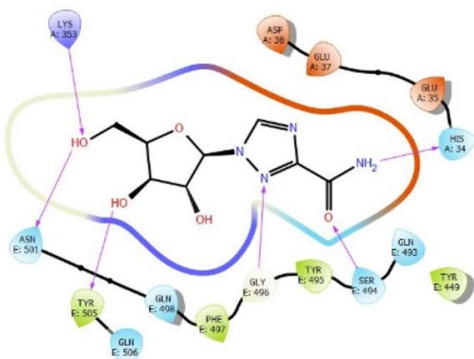

U
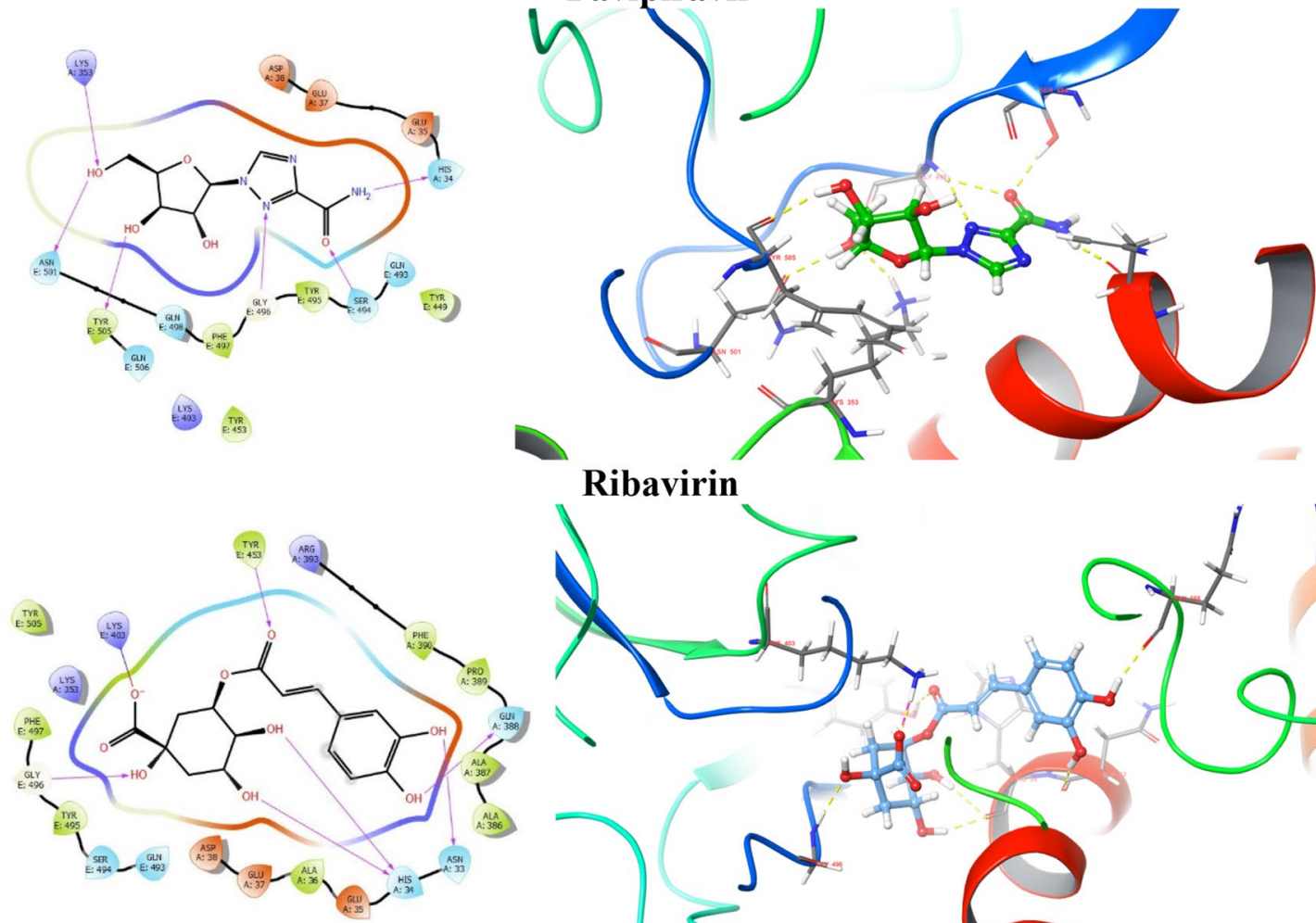

Ribavirin

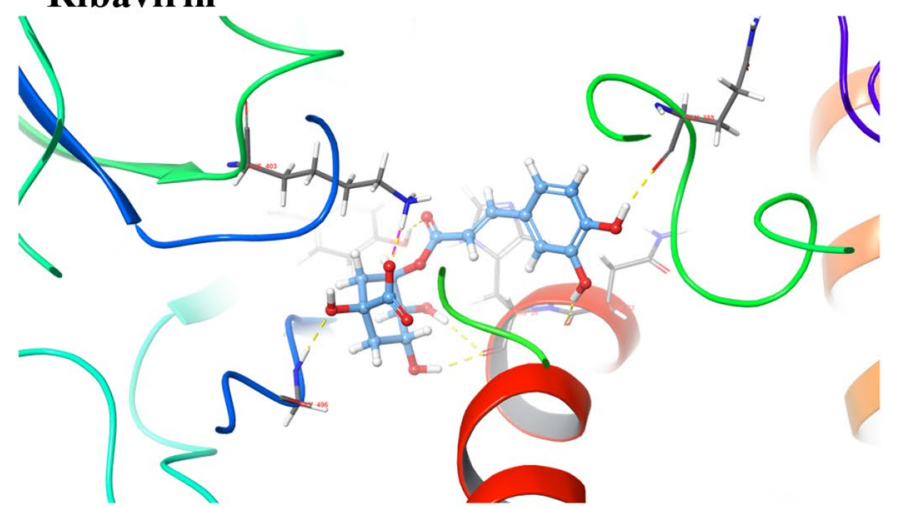

Iso-chlorogenic

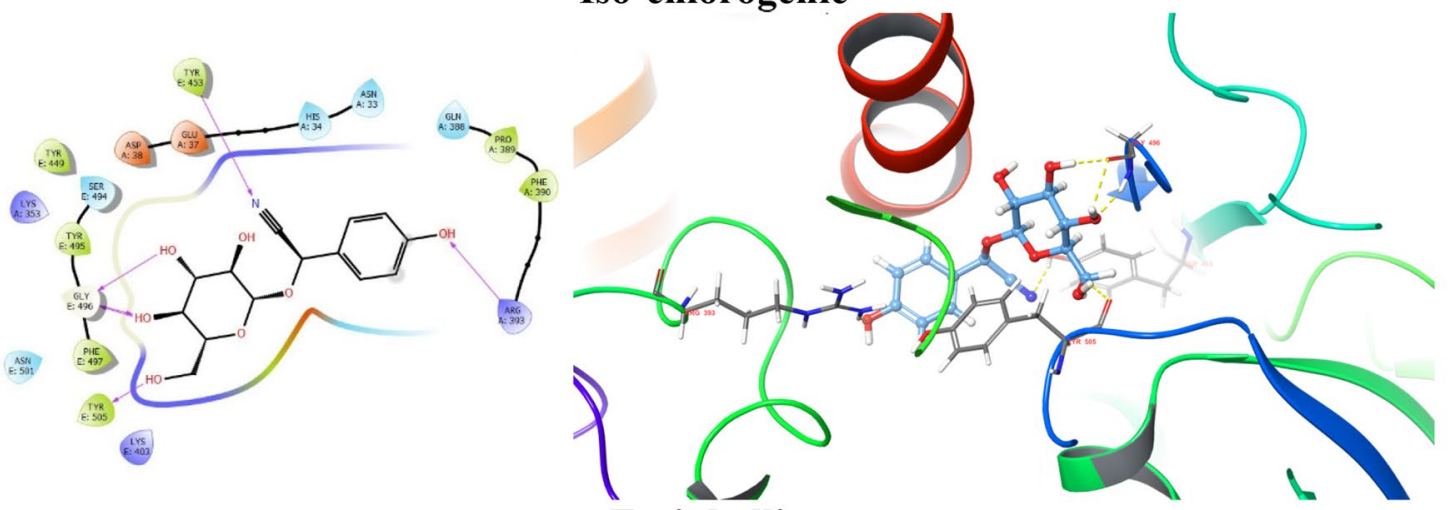

Taxiphyllin

Fig. $32 \mathrm{D}$ and 3D interaction diagram of favipiravir, ribavirin, iso-chlorogenic, taxiphyllin, vasicine, (+)-catechin and caffeic acid with the protein complex of SARs- CoV-2 RBD and ACE 2 showing the hydrogen bond (represented by yellow dotted line) and Pi-Pi stacking 

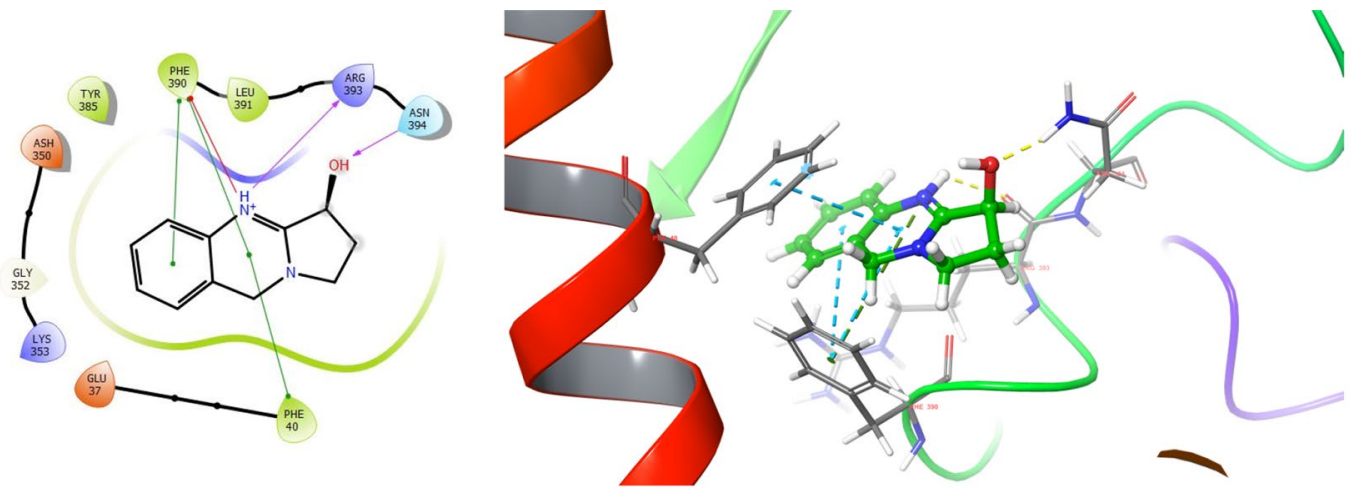

Vasicine
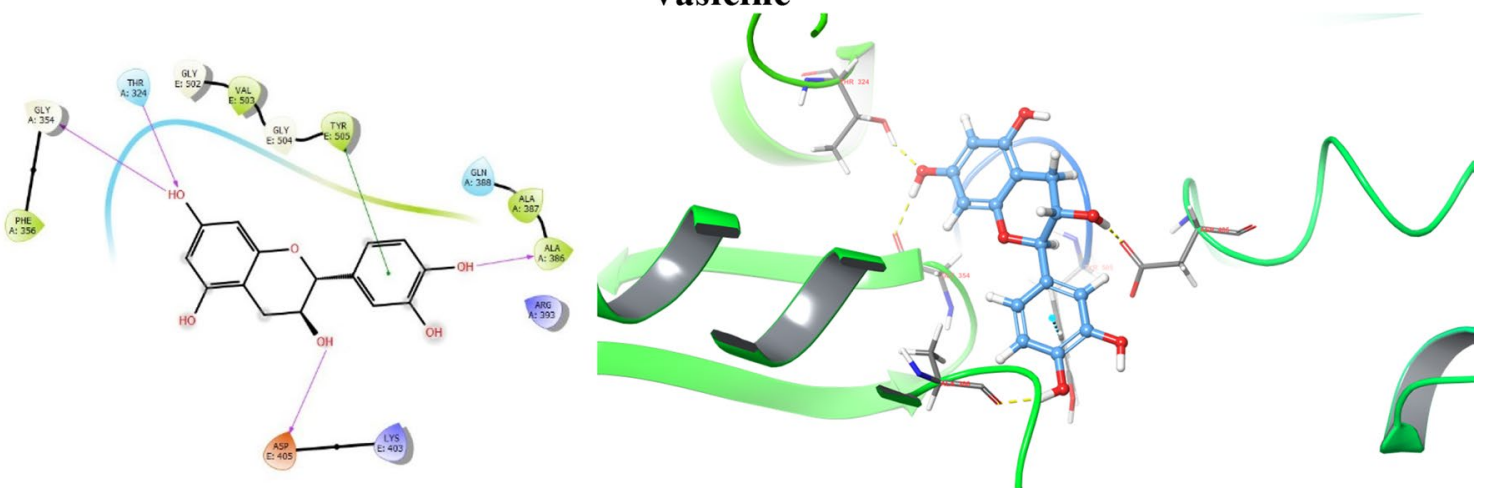

$(+)$-Catechin
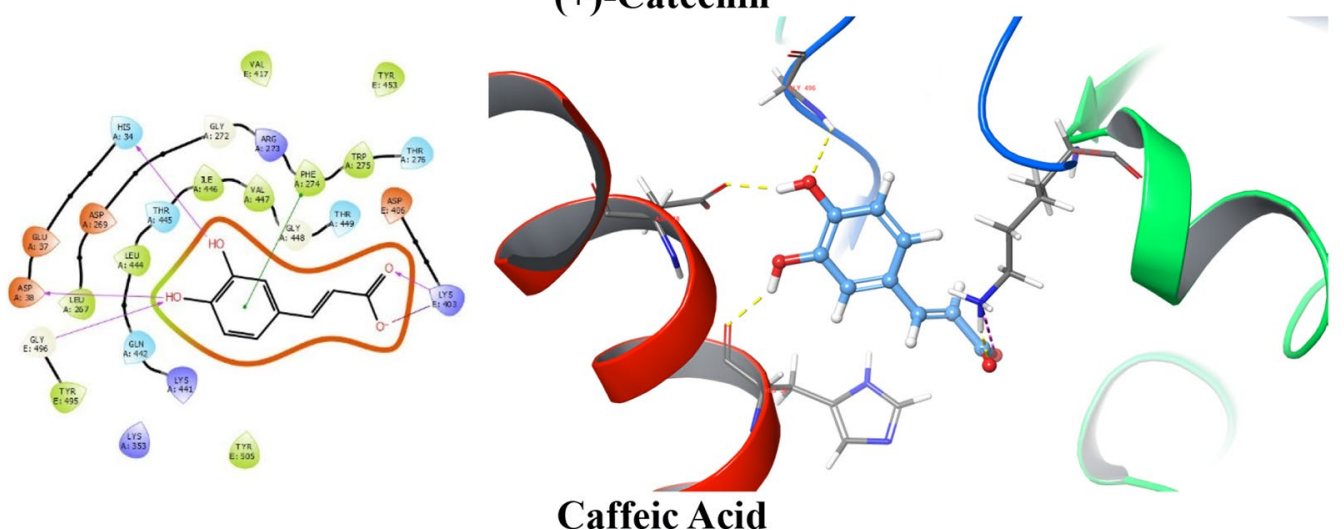

Fig. 3 (continued)

\section{Ligand docking}

Database of ligands created using selected Ayurvedic and Siddha formulation were docked using the extra precision docking protocol to obtain a correlation between a good pose of drugs and a high dock score. The top 10 ligands showing interaction with the amino acids analyzed by dimplot were selected and are listed in Table 2. The docking score of the standard drugs favipiravir and ribavirin had docking scores of -7.301 and $-4.807 \mathrm{kcal} / \mathrm{mol}$, respectively. The docking score of the top ten ligands ranged from -8.79 to $-4.86 \mathrm{kcal} / \mathrm{mol}$. Among them, iso-chlorogenic acid $(-8.79 \mathrm{kcal} / \mathrm{mol})$ showed the highest docking score by interacting with protein complex by forming a hydrogen bond with Gly E 496, Val E 417, Asp E 406, His A 34, and salt bridge with Arg E 408.

\section{Free ligand binding energy calculation}

After docking, the top 10 molecules selected based on docking score and interaction with residues, which are essential for binding ACE2 to SARS-CoV-2, were further analyzed for binding energy by MM-GBSA. The binding free energy of the standard drugs favipiravir and ribavirin was -36.3 and $-6.97 \mathrm{kcal} / \mathrm{mol}$. Ribavirin had the lowest binding 
Table 4 Summary of difference between interaction of ligands with protein complex in XP docking and induced fit docking

\begin{tabular}{|c|c|c|}
\hline Ligands & Interaction shown in XP docking & Interaction shown in induced fit docking \\
\hline Favipiravir & $\begin{array}{l}\text { H-bond: Phe E 497, Tyr E 453, Tyr E } 505 . \\
\text { Hydrophobic interaction } \\
\text { Charged negative: Asp A } 38 . \\
\text { Charged positive: Lys A } 353 \text {, Lys E } \mathbf{4 0 3 .} \\
\text { Hydrophobic: Tyr E } 495 \text {. } \\
\text { Polar: Gln E 498, Gln E } 493 \text {, Ser E 494, Asn E 501, His A } 34\end{array}$ & $\begin{array}{l}\text { H-bond: Gly E 496, Lys E } \mathbf{4 0 3} \text {, Tyr E } 505 . \\
\text { Salt bridge: Lys E } \mathbf{4 0 3} \text {. } \\
\text { Hydrophobic interaction } \\
\text { Charged negative: Asp A } 38 \text {, Glu A } 37 . \\
\text { Charged positive: Lys A } 353 \text {. Hydrophobic: Tyr E 495, Tyr E } \\
\text { 449, Tyr E 453, Phe E 497. } \\
\text { Polar: Asn E 501, Gln E 493, Ser E 494, Asn E 501, His A } 34\end{array}$ \\
\hline Ribavirin & $\begin{array}{l}\text { H-bond: Gly E 496, His A 34, Tyr E 453, Tyr E } 505 . \\
\text { Hydrophobic interaction } \\
\text { Charged negative: Glu A 37, Asp A } 38 . \\
\text { Charged positive: Lys A 353, Lys E 403, Arg A 393. Hydro- } \\
\text { phobic: Tyr E 495, Phe E 497. } \\
\text { Polar: Asn E 501, Gln E 506, Gln E 498, Gln E 493, Ser E } \\
\text { 494, Asn A 33 }\end{array}$ & $\begin{array}{l}\text { H-bond: Ser E 494, Asn E 501, Tyr E 505, Lys A 353, His } \\
\text { A } 34 . \\
\text { Hydrophobic interaction } \\
\text { Charged negative: Glu A 37, Asp A 38, Glu A } 35 . \\
\text { Charged positive: Lys A 353, Lys E 403. } \\
\text { Hydrophobic: Tyr E 495, Phe E 497, Tyr E 449, Tyr E } 453 . \\
\text { Polar: Gln E 506, Gln E 498, Gln E } 493\end{array}$ \\
\hline Iso-chlorogenic & $\begin{array}{l}\text { H-bond: Gly E 496, Val E 417, Asp E 406, His A } 34 \\
\text { Salt bridge: Arg E 408. } \\
\text { Hydrophobic interaction } \\
\text { Charged negative: Asp E 405, Glu A 37, Asp A } 38 . \\
\text { Charged positive: Lys A 353, Lys E 403. } \\
\text { Hydrophobic: Ile E 418, Tyr E 495, Tyr E 505, Tyr E 449, } \\
\text { Tyr E 453. } \\
\text { Polar: Gln E 409, Gln E 493, Ser E } 494\end{array}$ & $\begin{array}{l}\text { H-bond: Asn A 33, Gln A 388, Tyr E 453, His A 34, Lys E } \\
\text { 403, Gly E 496. } \\
\text { Salt bridge: Lys E 403. } \\
\text { Hydrophobic interaction } \\
\text { Charged negative: Glu E 35, Glu A 37, Asp A } 38 . \\
\text { Charged positive: Lys A 353, Arg A 393. } \\
\text { Hydrophobic: Phe A 390, Pro A 389, Ala A 387, Ala A 386, } \\
\text { Ala A 36, Tyr E 495, Phe E 497, Tyr E 505. } \\
\text { Polar: Gln E 493, Ser E } 494\end{array}$ \\
\hline Taxiphyllin & $\begin{array}{l}\text { H-bond: Arg A 393, Ala A 348, Ash A } 350 . \\
\text { Hydrophobic interaction } \\
\text { Charged negative: Glu A 37, Asp A 382. Charged positive: } \\
\text { Lys A } 353 . \\
\text { Hydrophobic: Trp A 349, Leu A 351, Phe A 40, Tyr A 385, } \\
\text { Phe A 390. } \\
\text { Polar: Hie 401, Asn A } 394\end{array}$ & $\begin{array}{l}\text { H-bond: Arg A 393, Tyr E 505, Tyr E 453, Gly E } 496 . \\
\text { Hydrophobic interaction } \\
\text { Charged negative: Glu A 37, Asp A } 38 . \\
\text { Charged positive: Lys A 353, Lys E } 403 \text {. } \\
\text { Hydrophobic: Phe A 390, Tyr E 449, Tyr E 495, Phe E 497, } \\
\text { Pro A 389. } \\
\text { Polar: Gln A 388, Asn A 33, His A 34, Ser E 494, Asn E } 501\end{array}$ \\
\hline Vasicine & $\begin{array}{l}\text { H-bond: Arg A 393, Asn A } 394 \text { Pi cation: Phe A 390, Phe A } \\
\text { 40. } \\
\text { Hydrophobic interaction } \\
\text { Charged negative: Ash A 350, Glu A } 37 \\
\text { Charged positive: Lys A } 353 \\
\text { Hydrophobic: Leu A 391, Tyr A 385, Leu A } 351\end{array}$ & $\begin{array}{l}\text { H-bond: Arg A 393, Asn A 394Pi cation: Phe A 390, Phe A } \\
\text { 40.Pi-Pi stacking: Phe A 390Hydrophobic interaction } \\
\text { Charged negative: Ash A 350, Glu A } 37 \\
\text { Charged positive: Lys A } 353 \\
\text { Hydrophobic: Leu A 391, Tyr A } 385\end{array}$ \\
\hline$(+)$-Catechin & $\begin{array}{l}\text { H-bond: Leu A 391, Arg A 393, Ash A } 350 . \\
\text { Hydrophobic interaction } \\
\text { Charged positive: Lys A } 353 . \\
\text { Hydrophobic: Phe A 40, Leu A 351, Phe A 390, Ala A 99, } \\
\text { Leu A 73, Trp A } 69 . \\
\text { Polar: Asn A } 394\end{array}$ & $\begin{array}{l}\text { H-bond: Ala A 386, Thr A 324, Gly A 354, Asp E } 405 . \\
\text { Pi-Pi stacking: Tyr E 505. } \\
\text { Hydrophobic interaction } \\
\text { Charged positive: Lys E 403, Arg A } 393 . \\
\text { Hydrophobic: Ala A 387, Val E 503, Phe A } 356 . \\
\text { Polar: Gln A } 388\end{array}$ \\
\hline Caffeic Acid & $\begin{array}{l}\text { H-bond: Gly E 496.Salt bridge: Lys E } 403 \\
\text { Hydrophobic interaction } \\
\text { Charged negative: Asp E 406, Glu A 37, Asp A } 38 . \\
\text { Charged positive: Lys A 353 } \\
\text { Hydrophobic: Tyr E 453, Tyr E 505, Tyr E 495, Phe E } 497 \\
\text { Polar: His A } 34\end{array}$ & $\begin{array}{l}\text { H-bond: His A 34, Asp A 38, Gly E 496, Lys E } 403 \\
\text { Salt bridge: Lys E 403 } \\
\text { Pi-Pi stacking: Phe A 274.Hydrophobic interaction } \\
\text { Charged negative: Asp E 406, Glu A 37, Asp A } 269 \\
\text { Charged positive: Lys A 353, Lys A 441, Arg A } 273 . \\
\text { Hydrophobic: Tyr E 453, Tyr E 505, Tyr E 495, Leu A 267, } \\
\text { Leu A 444, Ile A 446, Val A 447, Trp A 275, Val E } 471 \\
\text { Polar: Gln A 442, Thr A 445, Thr A 276, Thr A } 449\end{array}$ \\
\hline
\end{tabular}

energy among all the selected ligands. The free ligand binding energy of all selected ligands ranged from -18.01 to $-40.77 \mathrm{kcal} / \mathrm{mol}$, highest shown by Vasicine. All ligands except caffeic acid and iso-chlorogenic acid had binding energy of more than $-20 \mathrm{kcal} / \mathrm{mol}$.

\section{ADME analysis}

ADME properties of the selected ligands were predicted by using the Qikprop module. The assessment was done using various descriptor calculations as tabulated in Table 3 like QPlogPo/w, QPlogS, QPPCaco, QPlogHERG, 

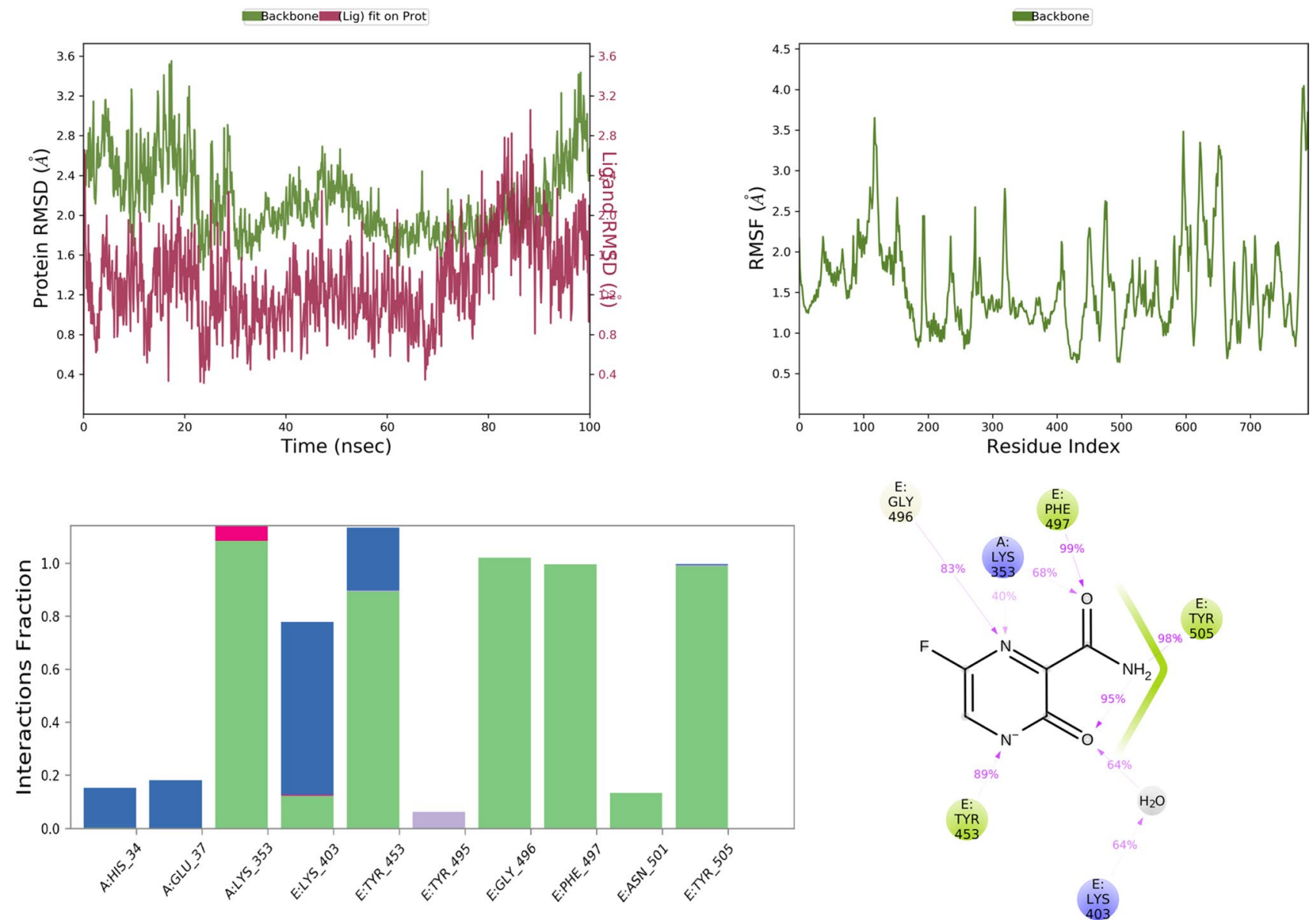

Fig. 4 RMSD, RMSF, and protein-ligand contact plots of favipiravir with protein complex of SARS-CoV-2 chimeric receptor-binding domain and angiotensin-converting enzyme 2 observed during MD simulation

$\%$ human oral absorption, PSA, and Lipinski rule of five. All ligands did not violate the rule of five, showing druglike property. All selected ligands have good aqueous solubility, hydrophobic and hydrophilic balance as predicted by QPlogS and QPLogPo/w vales, respectively. The QPPCaco and \% oral absorption of all molecules except iso-chlorogenic acid were within the acceptable range. The QlogHERG values were more than -5; therefore, ligands have not shown the potential to inhibit the hERG potassium channel.

\section{Induced fit docking (IFD)—SP}

After analyzing the docking score, glide energy, dG bind score, ADME, and the interactions with the protein, top 5 ligands, and standard drugs were further studied by using Induced fit docking protocol. IFD analysis involves flexible docking that helps to confirm whether there are any changes in the binding of ligands at different poses with the amino acid residues of the target protein complex. Maximum 20 possible poses were generated for favipiravir, ribavirin, iso-chlorogenic acid, taxiphyllin, vasicine, catechin, and caffeic acid by providing flexibility to the ligand and amino acid residue of the protein complex. Further, ligand interaction with the key residues was analyzed for selecting pose for molecular dynamics. The 2D and 3D ligand interactions obtained after IFD are represented in Fig. 3. There were many differences in interaction seen in the XP docking pose and IFD pose, which is highlighted in Table 4.

Favipiravir showed H-bond with Gly E 496 in the IFD pose, which is one of the key residues, in addition to retaining Tyr E 505. Ribavirin retained $\mathrm{H}$-bond interaction with Tyr E 505 and formed H-bond with Lys A 353. For Isochlorogenic acid, no new interaction with key residue was formed, and H-bond interaction with Gly E 496 was retained. Taxiphyllin formed H-bond interaction with Tyr E 505, Gly E 496, which are essential for binding to ACE2. In the case of Vasicine, no interaction with any key residue was seen even in the IFD pose. Catechin had not shown any important interaction in the XP docked pose, but in the IFD pose, it showed Pi-Pi stacking type of interaction with Tyr E 505. Caffeic acid showed new H-bond interaction with Asp A 38 

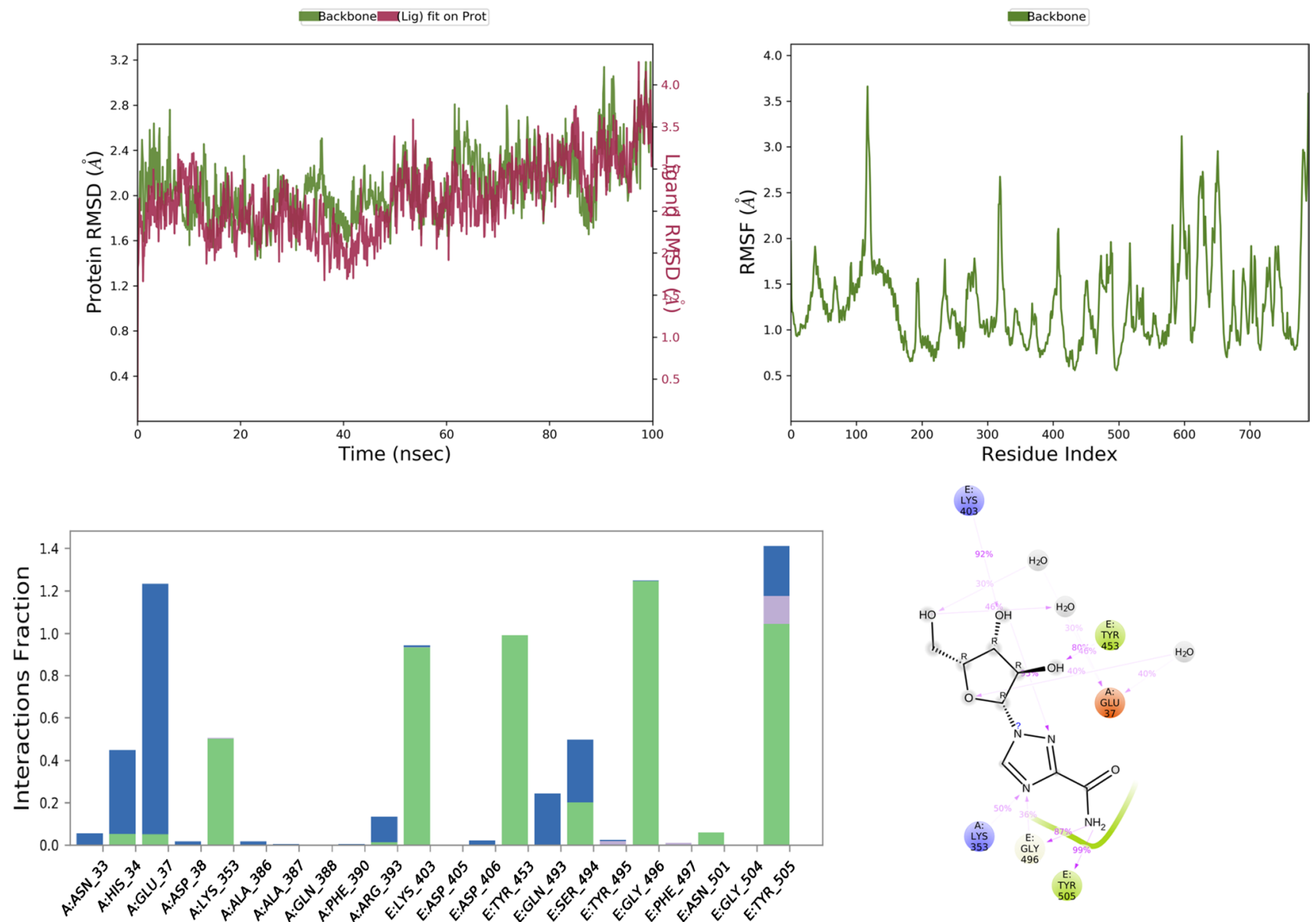

Fig. 5 RMSD, RMSF, and protein-ligand contact plots of ribavirin with protein complex of SARS-CoV-2 chimeric receptor-binding domain and angiotensin-converting enzyme 2 observed during MD simulation

retaining Gly E 496. This change in the interaction between XP docking pose and IFD pose of the ligands may be due to the mobility of the protein amino acid chains, which is not seen in the XP docking; hence the pose showing interaction with key residues were selected for MD docking studies.

\section{Molecular Dynamics (MD) simulation analysis of the compounds with thermal}

\section{MM-GBSA}

MD simulation study mimics the physiological condition, thereby, providing information related to protein-ligand interactions with biological significance. Currently, MD simulation was done for standard drugs and selected top five docking score favipiravir, ribavirin, iso-chlorogenic acid, taxiphyllin, vasicine, catechin, and caffeic acid. Results of the MD simulation are represented in Figs. 4, 5, 6, 7, 8, 9, and 10 in order of name of ligands mentioned above.

The RMSD plot analysis of the MD simulation showed that protein structure in all the simulations was stable with RMSD less than $5 \AA$ A. Still, after analyzing ligand RMSD, it was found that all ligands except vasicine (ligand RMSD 0.5-12 $\AA$ ) were stable during molecular simulations, which means vasicine was not able to form a stable interaction with the protein (Table 5).

Favipiravir bound to the protein exhibited a combination of hydrogen bond, water bridge, and bonding interactions. 

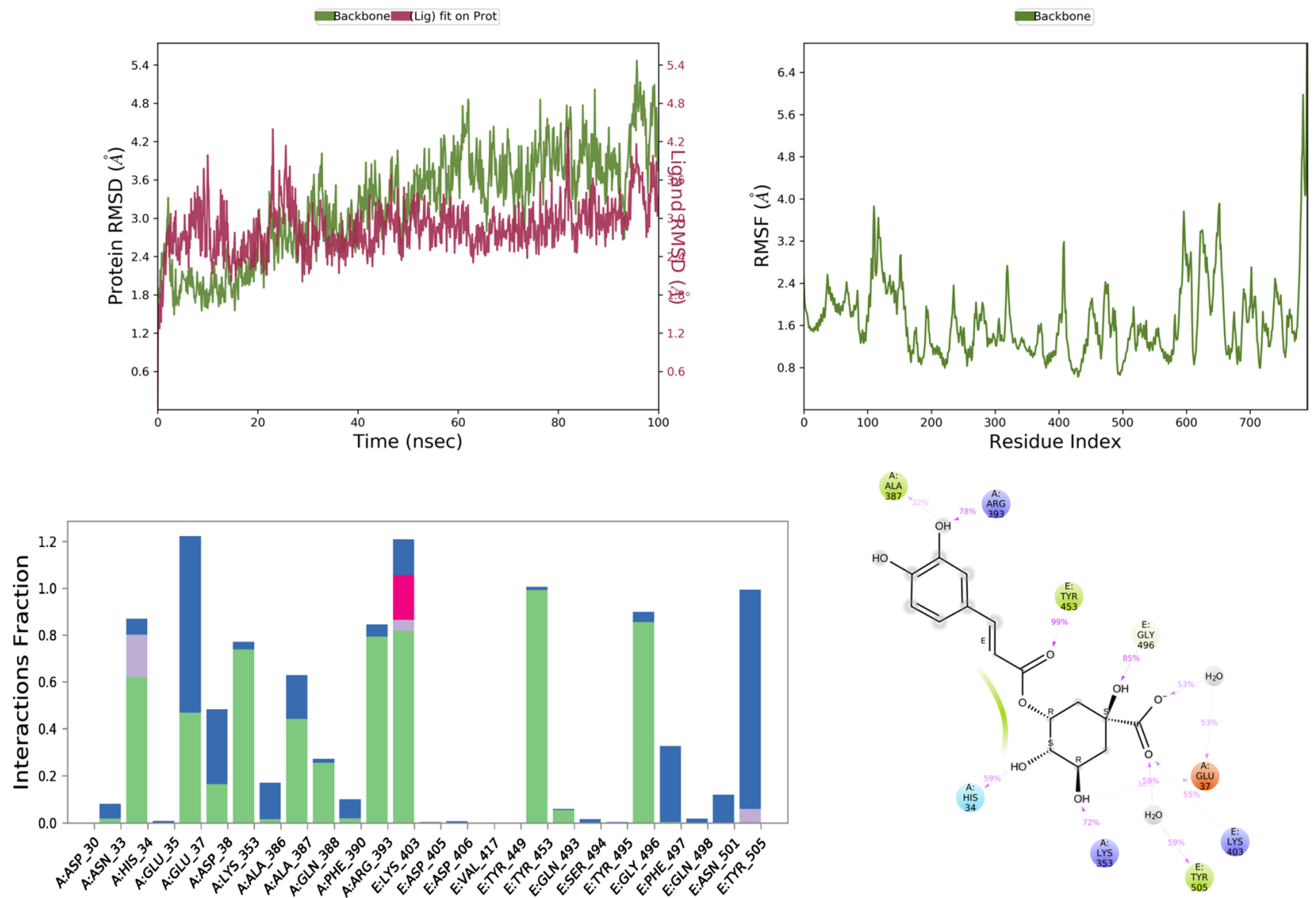

Fig. 6 RMSD, RMSF, and protein-ligand contact plots of iso-chlorogenic acid with protein complex of SARS-CoV-2 chimeric receptor-binding domain and angiotensin-converting enzyme 2 observed during MD simulation

Among them, it showed H-bond interaction with key residues like Tyr E 505 and Gly E 496 for more than $80 \%$ of the time of MD simulation, as seen in Fig. 4. Ribavirin showed interaction with Tyr E 505 (99\%), Glu A 37 (40\%), Lys A 353 (50\%), Gly E 496 (87\%), for Tyr E 505, Gly E 496, Lys A 353 it was mostly H-bond mediated interaction, but for Glu A 37 it was water bridge mediated interaction as seen in Fig. 5.

Among all test ligands, iso-chlorogenic acid showed the maximum number of interactions with the protein. Interactions with key residue similar to ribavirin like Tyr E 505, Glu A 37, Lys A 353, Gly E 496 were present. Still, the type of interactions was different, Tyr E 505 was mostly water bridge (59\%) mediated interactions, Glu A 37 was both water bridge (53\%) and $\mathrm{H}$-bond mediated (38\%) interactions, Gly E 496, Lys A 353 were H-bond mediated for $85 \%$ and $72 \%$ of the time, respectively, as seen in Fig. 6 . Though the taxiphyllin-protein complex was very stable, it formed interaction with only two key residues Tyr E 505, Lys A 353; both were mostly H-bond types of interaction for $57 \%$ and $76 \%$ of the time as seen in Fig. 7. Vasicine didn't show interaction with any of the key residues, and the protein-ligand complex was also not stable, as shown in Fig. 8. Catechin showed interactions with Tyr E 505 for $69 \%$ of the time, which was the hydrophobic type; Glu A 38 showed H-bond type interaction with two different hydroxyl groups of catechin and Gly E 496 showed H-bond interaction for $88 \%$ of the time as seen in Fig. 9. Caffeic acid interacted with only two amino acids Tyr E 505 (hydrophobic) and Gly A 37 (H-bond), for a period of $80 \%$ and $95 \%$ of the time, as shown in Fig. 10.

Thermal MM-GSBA was performed using the trajectory generated after MD simulation. The average binding energy of all the ligands was more than $-25 \mathrm{kcal} / \mathrm{mol}$ except vasicine $(1973.84 \mathrm{kcal} / \mathrm{mol})$, which showed positive value proving that the protein-ligand complex was not 

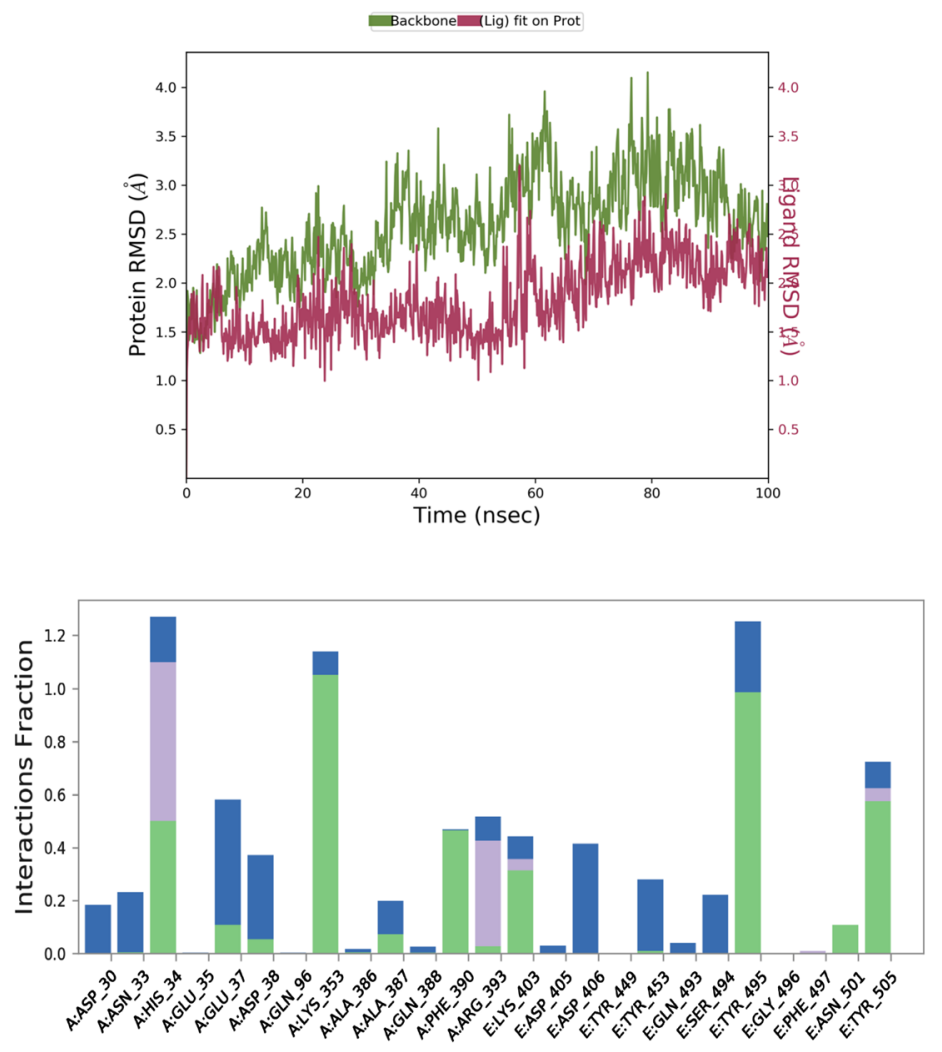
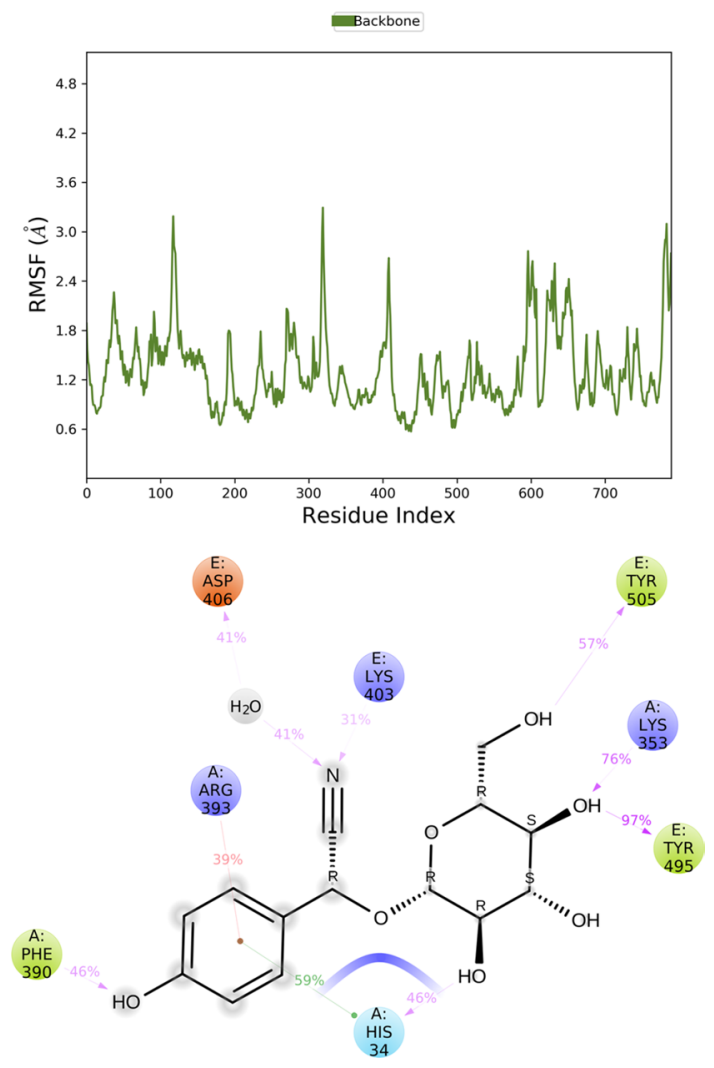

Fig. 7 RMSD, RMSF, and protein-ligand contact plots of taxiphyllin with protein complex of SARS-CoV-2 chimeric receptor-binding domain and angiotensin-converting enzyme 2 observed during MD simulation

stable. The most stable complex among all was ribavirin with $-49.8 \mathrm{kcal} / \mathrm{mol}$. Iso-chlorogenic acid, which showed the maximum number of interactions with key residue, had average binding energy of $-46.68 \mathrm{kcal} / \mathrm{mol}$.

\section{Discussion}

In this work, an in silico approach is used to evaluate the traditional formulation of Siddha and Ayurveda system of medicine like Kabasura Kudineer, Shwas Kuthar Rasa with Kantakari and Pippali churna, Talisadi churna selected from the advisory issued by the ministry of Ayush for management of COVID-19 pandemic. After performing docking, ADME prediction, free binding energy determination, we narrowed it down to the top five phytoconstituents iso-chlorogenic acid, taxiphyllin, vasicine, catechin, and caffeic acid. On a literature survey, it was found that vasicine has shown activity against Influenza Virus Infection (Chavan et al. 2013). Iso-chlorogenic acid has a potent anti-hepatitis B activity (Hao et al. 2012), and antienterovirus (Cao et al.
2017), one of its derivate iso-chlorogenic acid A has been proven by the in vitro study to inhibit viral entry into the cell at 100 micromolar concentration (Zhang et al. 2021). Catechin inhibits both Mpro and spike protein of SARSCoV-2 predicted by using computational study (Srivastava et al. 2020). Caffeic acid was able to impair the binding interaction of human coronavirus NL63 (HCoV-NL63) with ACE2 receptor (IC50 $=3.54 \mu \mathrm{M})$ (Weng et al. 2019). In this study, we have tried to identify phytoconstituents showing better binding efficacy with S-protein RBD complex with ACE2 and to compare its binding with already approved drugs like ribavirin and favipiravir. MD simulation and thermal MM-GBSA were performed. By MD, we got to know that iso-chlorogenic acid showed stable interaction with the key residues like that of the ribavirin and had RMSD in the acceptable range, which was further confirmed by the thermal MM-GBSA result proving that iso-chlorogenic acid forms a more stable complex with the target protein. All other top five phytoconstituents except vasicine formed stable interaction with key residues as discussed in results showing that many phytoconstituents might be able to inhibit 

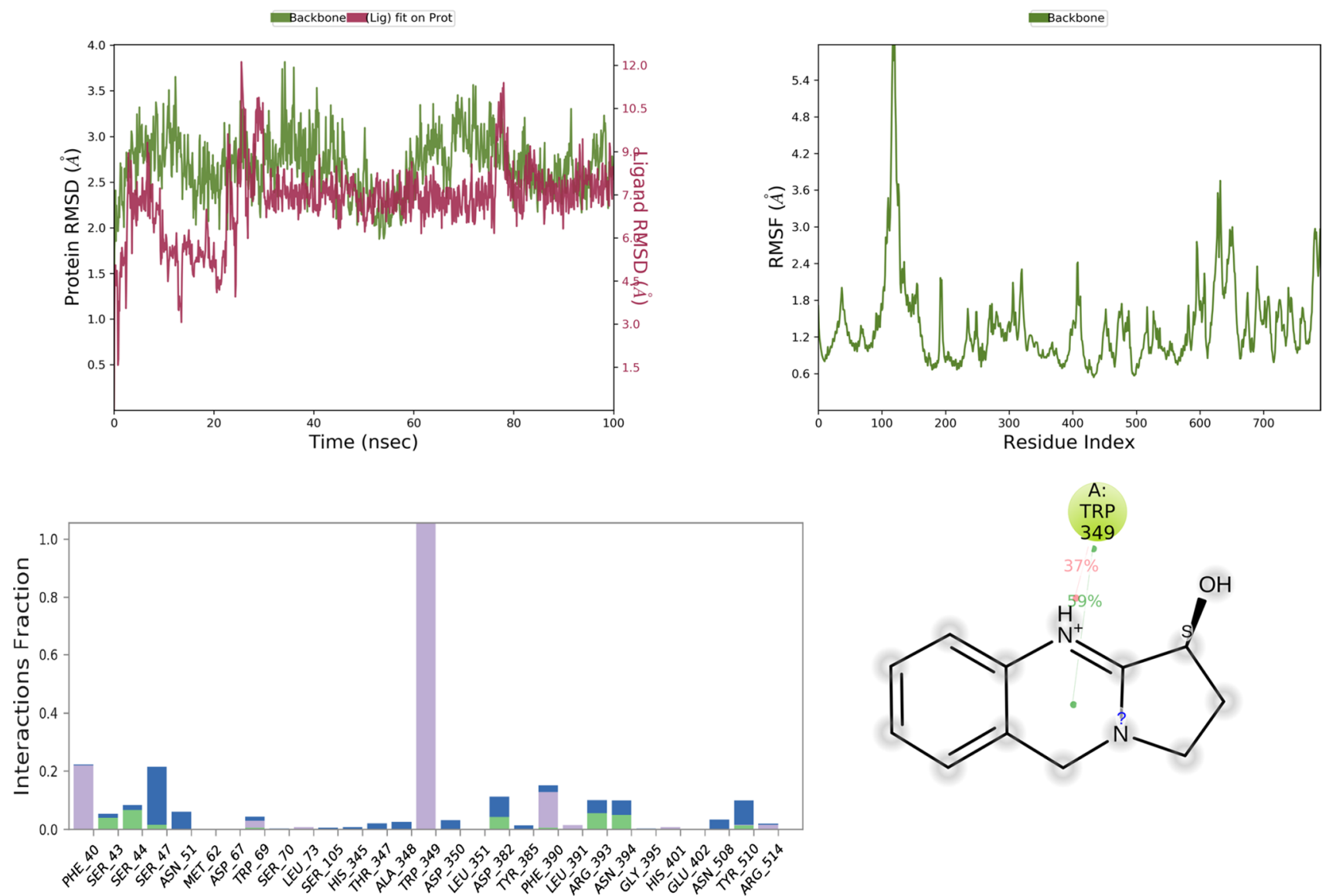

Fig. 8 RMSD, RMSF, and protein-ligand contact plots of vasicine with protein complex of SARS-CoV-2 chimeric receptor-binding domain and angiotensin-converting enzyme 2 observed during MD simulation

the entry of the virus into the cell. When compared to other similar studies published recently with PDB ID 6VW1, we found that (Morgon et al. 2021) showed that (S)-Linezolid had a binding affinity of $-8.05 \mathrm{kcal} / \mathrm{mol}$ with no interaction with key residues. However, in our study iso-chlorogenic acid $(-8.799 \mathrm{kcal} / \mathrm{mol})$ had interaction with key residues with higher binding affinity. In another study by Junaid et al. (2021), docking of Vitamin B, C, D was done and the binding energy $-9.18,-12.75,-7.92$, respectively, was reported, interaction with key residue His A 353 was only observed for vitamin C.
This provides molecular bases for using the traditional Siddha- and Ayurvedic-based classical formulations for treating COVID-19. It also helps the researcher develop more potent molecules that can be used to control the spreading of the pandemic and mass-produce the drug molecule. Therefore, we made a small effort to identify the molecule which can inhibit the entry of COVID-19 through ACE2 receptor into the cell by using phytoconstituents present in Ayurvedic and Siddha formulation advised by the Ministry of Ayush. 

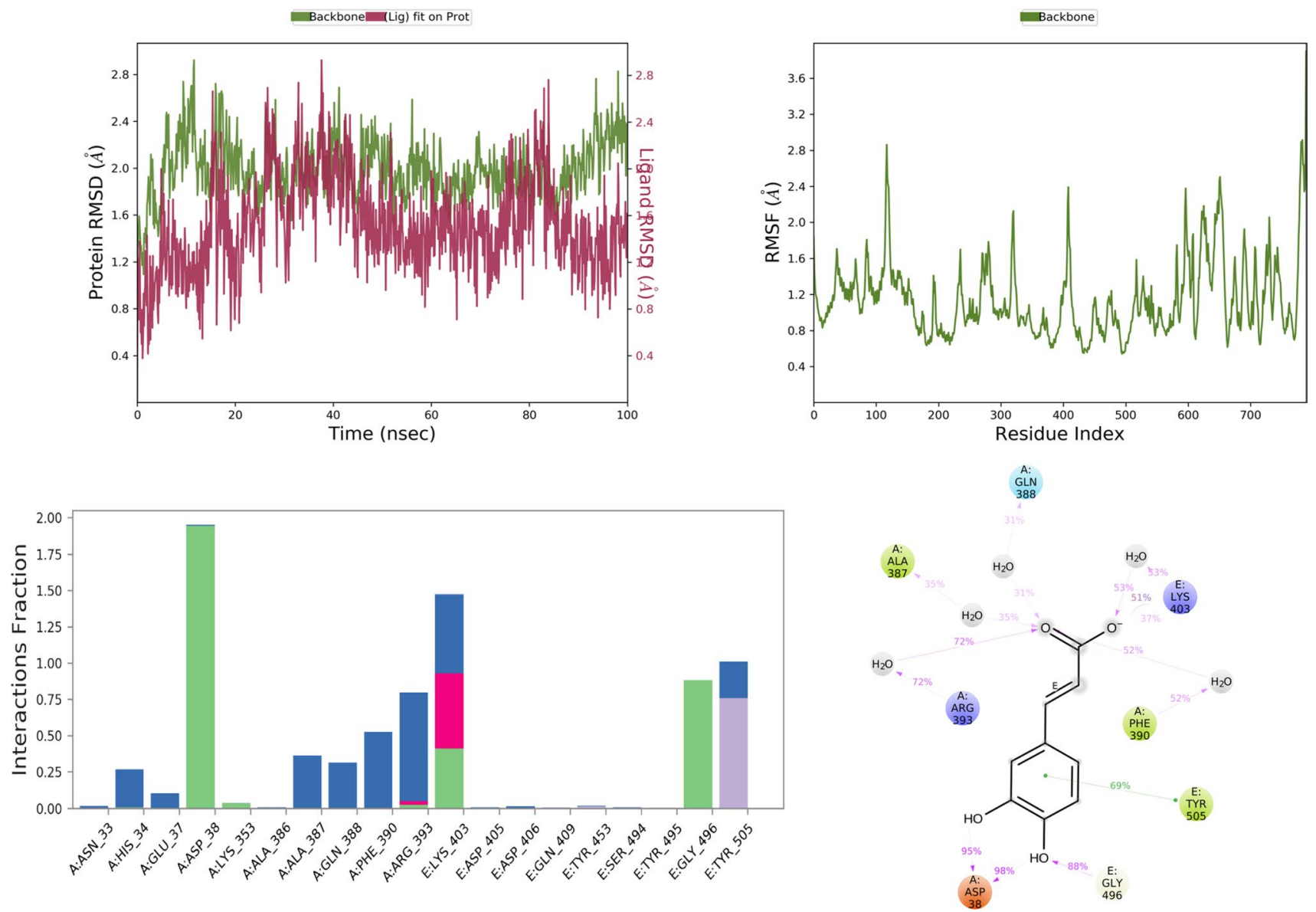

Fig. 9 RMSD, RMSF, and protein-ligand contact plots of (+)-catechin with protein complex of SARS-CoV-2 chimeric receptor-binding domain and angiotensin-converting enzyme 2 observed during MD simulation

\section{Conclusion}

The spike protein of COVID-19 has been proven to assist the entry of the virus into the cell more easily compared to its counterpart in the family of the SARS virus. Inhibition of binding of spike protein to the ACE2 of the host cell is one of the best possible approaches which can be used to prevent the spreading of the infection by COVID-19. In this study, we have used in silico molecular docking studies for the 133 phytoconstituents selected from Ayurvedic and Siddha formulation against the protein of SARS-CoV-2 RBD complexed with ACE2 receptor (PDB ID: 6VW1). The results showed that iso-chlorogenic has a similar binding affinity and high binding interactions with the amino acid residues involved in binding of SARS-CoV-2 RBD with the ACE2 receptor compared to favipiravir and ribavirin. Further, in silico pharmacokinetic and toxicity prediction has shown poor oral bioavailability and is free from toxicity. Based on this, we can say that iso-chlorogenic acid among all phytoconstituent in the selected formulation has the ability to inhibit the entry of the COVID-19 into the host cell. However, further In vitro and In vivo studies are required to confirm the findings. 

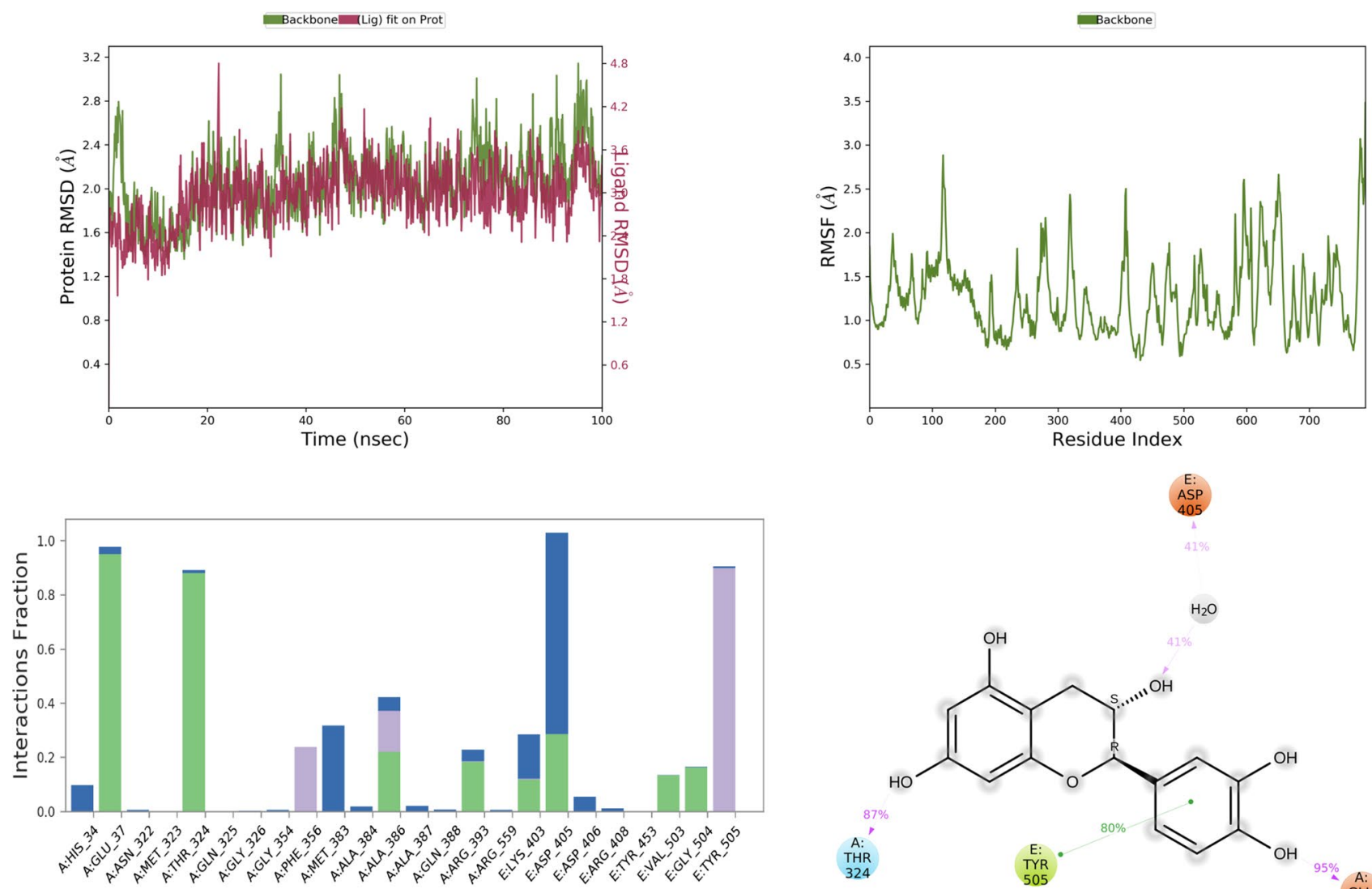

Fig. 10 RMSD, RMSF, and protein-ligand contact plots of caffeic acid with protein complex of SARS-CoV-2 chimeric receptor-binding domain and angiotensin-converting enzyme 2 observed during MD simulation

Table 5 Thermal MM-GBSA analysis of the top five ligands iso-chlorogenic acid, taxiphyllin, vasicine, catechin, and caffeic acid and standard drug molecules

\begin{tabular}{|c|c|c|c|}
\hline Sl No. & Name & $\begin{array}{l}\text { Average binding energy in } \\
\mathrm{Kcal} / \mathrm{mol}\end{array}$ & $\begin{array}{l}\text { Maximum binding energy } \\
\text { among all frame in Kcal/ } \\
\text { mol }\end{array}$ \\
\hline & Favipiravir & -33.15 & -41.61 \\
\hline & Ribavirin & -49.80 & -61.84 \\
\hline & Iso-chlorogenic acid & -46.68 & -82.24 \\
\hline & Vasicine & 1973.84 & -57.61 \\
\hline & Taxiphyllin & -44.57 & -63.28 \\
\hline & Catechin & -47.28 & -55.14 \\
\hline & Caffeic acid & -28.54 & -37.63 \\
\hline
\end{tabular}

Supplementary Information The online version contains supplementary material available at https://doi.org/10.1007/s11696-021-01917-z.

Acknowledgements The authors are thankful to Manipal - Schrödinger Centre for Molecular Simulations, Manipal Academy of Higher Education, Department of Pharmaceutics, Manipal College of Pharmaceutical Sciences facilitating the computer simulations (DST-SERB, New Delhi, India EMR/2016/007006) and Manipal College of Pharmaceutical Sciences for providing the necessary support and research facilities to carry out the present research work.
Funding Open access funding provided by Manipal Academy of Higher Education, Manipal.

\section{Declarations}

Conflict of interest The authors declare that they have no conflict of interest.

Open Access This article is licensed under a Creative Commons Attribution 4.0 International License, which permits use, sharing, adaptation, distribution and reproduction in any medium or format, as long 
as you give appropriate credit to the original author(s) and the source, provide a link to the Creative Commons licence, and indicate if changes were made. The images or other third party material in this article are included in the article's Creative Commons licence, unless indicated otherwise in a credit line to the material. If material is not included in the article's Creative Commons licence and your intended use is not permitted by statutory regulation or exceeds the permitted use, you will need to obtain permission directly from the copyright holder. To view a copy of this licence, visit http://creativecommons.org/licenses/by/4.0/.

\section{References}

Bowers KJ, Chow DE, Xu H, Dror RO, Eastwood MP, Gregersen BA, Klepeis JL, Kolossvary I, Moraes MA, Sacerdoti FD et al. (2006) Scalable Algorithms for Molecular Dynamics Simulations on Commodity Clusters. ACM/IEEE SC 2006 Conference (SC'06). IEEE, 43-43

Cao Z, Ding Y, Cao L, Ding G, Wang Z, Xiao W (2017) Isochlorogenic acid $\mathrm{C}$ prevents enterovirus 71 infection via modulating redox homeostasis of glutathione. Sci Rep 7:16278

Cascella M, Rajnik M, Cuomo A, Dulebohn SC and Di Napoli R (2020) Features, Evaluation and Treatment Coronavirus (COVID-19).

Chavan R, Gohil D, Shah V, Kothari S, Chowdhary A (2013) Antiviral activity of Indian medicinal plant Justicia Adhatoda against herpes simplex virus: an In-Vitro study. Int J Pharma Bio Sci 4:769-778

Friesner RA, Murphy RB, Repasky MP, Frye LL, Greenwood JR, Halgren TA, Sanschagrin PC, Mainz DT (2006) Extra precision glide: docking and scoring incorporating a model of hydrophobic enclosure for protein-ligand complexes. J Med Chem 49:6177-6196. https://doi.org/10.1021/jm051256o

Gautret P, Lagier JC, Parola P, Hoang VT, Meddeb L, Mailhe M, Doudier B, Courjon J, Giordanengo V, Vieira VE et al (2020) Hydroxychloroquine and azithromycin as a treatment of COVID-19: results of an open-label non-randomized clinical trial. Int J Antimicrob Agents 56:105949. https://doi.org/10. 1016/j.ijantimicag.2020.105949

(2020c) Guidelines for Ayurveda practitioners for COVID 19.

(2020b) Guidelines for Siddha practitioners for COVID 19.

Guo YR, Cao QD, Hong ZS, Tan YY, Chen SD, Jin HJ, Sen TK, Wang DY, Yan Y (2020) The origin, transmission and clinical therapies on coronavirus disease 2019 (COVID-19) outbreak- An update on the status. Mil Med Res 7:11. https://doi.org/10.1186/ s40779-020-00240-0

Halgren T (2007) New method for fast and accurate binding-site identification and analysis. Chem Biol Drug Des 69:146-148. https:// doi.org/10.1111/j.1747-0285.2007.00483.x

Halgren TA (2009) Identifying and characterizing binding sites and assessing druggability. J Chem Inf Model 49:377-389. https:// doi.org/10.1021/ci800324m

Halgren TA, Murphy RB, Friesner RA, Beard HS, Frye LL, Pollard WT, Banks JL (2004) Glide: a new approach for rapid, accurate docking and scoring. 2. Enrichment factors in database screening. J Med Chem 47:1750-1759. https://doi.org/10.1021/jm030644s

Hao BJ, Wu YH, Wang JG, Hu SQ, Keil DJ, Hu HJ, Lou JD, Zhao Y (2012) Hepatoprotective and antiviral properties of isochlorogenic acid A from Laggera alata against hepatitis B virus infection. J Ethnopharmacol 144:190-194. https://doi.org/10.1016/j.jep.2012. 09.003

Huang Y, Yang C, XX feng Xu W and Liu S wen, (2020) Structural and functional properties of SARS-CoV-2 spike protein: potential antivirus drug development for COVID-19. Acta Pharmacol Sin. https://doi.org/10.1038/s41401-020-0485-4 (2021b) \#IndiaFightsCorona COVID-19. In: Gov. India. https://www. mygov.in/covid-19/.

Janadri S, Mishra AP, Kumar R, Shanmukh I, Rao N, Kharya M (2015) Preparation and characterization of mercury-based traditional herbomineral formulation: shwas kuthar rasa. J Ayurveda Integr Med 6:268-272. https://doi.org/10.4103/0975-9476. 172383

Junaid K, Qasim S, Yasmeen H, Ejaz H, Alsrhani A, Ullah MI, Ahmad F, Rehman A (2021) Potential inhibitory effect of vitamins against COVID-19. Comput Mater Contin 66:707-714

Kiran G, Karthik L, Shree Devi MS, Sathiyarajeswaran P, Kanakavalli K, Kumar KM, Ramesh Kumar D (2020) In Silico computational screening of Kabasura Kudineer - Official Siddha Formulation and JACOM against SARS-CoV-2 spike protein. J Ayurveda Integr Med. https://doi.org/10.1016/j.jaim.2020.05.009

Laskowski RA, Swindells MB (2011) LigPlot+: Multiple ligandprotein interaction diagrams for drug discovery. J Chem Inf Model 51:2778-2786. https://doi.org/10.1021/ci200227u

MadhaviSastry G, Adzhigirey M, Day T, Annabhimoju R, Sherman W (2013) Protein and ligand preparation: Parameters, protocols, and influence on virtual screening enrichments. J Comput Aided Mol Des 27:221-234. https://doi.org/10.1007/s10822-013-9644-8

Margaret Harris; Daniela Bagozzi (2020) WHO discontinues hydroxychloroquine and lopinavir/ritonavir treatment arms for COVID-19. World Heal Organ News Release 2020

Morgon NH, Grandini GS, Yoguim MI, Porto CM, Santana LC, Biswas S, de Souza AR (2021) Potential activity of Linezolid against SARS-CoV-2 using electronic and molecular docking study. J Mol Model 27:222. https://doi.org/10.1007/s00894-021-04828-8

Patra KC, Kumar PS, Singh B, Kumar KJ (2011) Comparative standardization of a polyherbal ayurvedic formulation talishadi churna. Indian J Tradit Knowl 10:608-611. https://doi.org/10. 5958/0975-4385.2015.00008.4

(2020a) Operational Planning Guidelines To Support Country Preparedness and Response. World Heal Organ 13:17.

Puthiyedath R, Kataria S, Payyappallimana U, Mangalath P, Nampoothiri V, Sharma P, Singh MK, Kumar K, Trehan N (2020) Ayurvedic clinical profile of COVID-19 - A preliminary report. J Ayurveda Integr Med. https://doi.org/10.1016/j.jaim.2020.05. 011

Rastogi S, Pandey DN, Singh RH (2020) COVID-19 pandemic: A pragmatic plan for ayurveda intervention. J Ayurveda Integr Med. https://doi.org/10.1016/j.jaim.2020.04.002

Shang J, Ye G, Shi K, Wan Y, Luo C, Aihara H, Geng Q, Auerbach A, Li F (2020) Structural basis of receptor recognition by SARS-CoV-2. Nature 581:221-224. https://doi.org/10.1038/ s41586-020-2179-y

Sherman W, Beard HS, Farid R (2006a) Use of an induced fit receptor structure in virtual screening. Chem Biol Drug Des 67:8384. https://doi.org/10.1111/j.1747-0285.2005.00327.x

Sherman W, Day T, Jacobson MP, Friesner RA, Farid R (2006b) Novel procedure for modeling ligand/receptor induced fit effects. J Med Chem 49:534-553. https://doi.org/10.1021/jm050 $540 \mathrm{c}$

Singh R, Vijayan V (2020) Chloroquine: a potential drug in the COVID-19 scenario. Trans Indian Natl Acad Eng 5:399-410. https://doi.org/10.1007/s41403-020-00114-w

Srivastava R, Tripathi S, Unni S, Hussain A, Haque S, Dasgupta N, Singh V, Mishra BN (2020) Silybin B and cianidanol inhibit M pro and Spike Protein of SARS-CoV-2: evidence from in silico molecular docking studies. Curr Pharm Des. https://doi.org/10. 2174/1381612826666201210122726

Kaba Suram (Swine Flu). In: Natl. Heal. Portal India. https://www. nhp.gov.in/swine-flu_mtl.

Tekuri SK, Pasupuleti SK, Konidala KK, Amuru SR, Bassaiahgari P, Pabbaraju N (2019) Phytochemical and pharmacological 
activities of Solanum surattense Burm. f.-A review. J Appl Pharm Sci 9:126-136. https://doi.org/10.7324/JAPS.2019. 90318

Weng JR, Lin CS, Lai HC, Lin YP, Wang CY, Tsai YC, Wu KC, Huang SH, Lin CW (2019) Antiviral activity of Sambucus FormosanaNakai ethanol extract and related phenolic acid constituents against human coronavirus NL63. Virus Res 273:197767. https://doi.org/10.1016/j.virusres.2019.197767

(2021a) Worldometer. https://www.worldometers.info/coronaviru s/?fbclid=IwAR35ZFiRZJ8tyBCwazX2N-k7yJjZOLDQiZSA MsJAfdK74s8f2a_Dgx4iVk.

Zhang D, Hamdoun S, Chen R, Yang L, Ip CK, Qu Y, Li R, Jiang H, Yang Z, Chung SK et al (2021) Identification of natural compounds as SARS-CoV-2 entry inhibitors by molecular docking-based virtual screening with bio-layer interferometry. Pharmacol Res 172:105820. https://doi.org/10.1016/j.phrs. 2021.105820

Zhou P, Lou YX, Wang XG, Hu B, Zhang L, Zhang W, Si HR, Zhu Y, Li B, Huang CL et al (2020) A pneumonia outbreak associated with a new coronavirus of probable bat origin. Nature 579:270-273. https://doi.org/10.1038/s41586-020-2012-7

Publisher's Note Springer Nature remains neutral with regard to jurisdictional claims in published maps and institutional affiliations. 